University of Zurich

Department of Economics

Working Paper Series

ISSN 1664-7041 (print)

ISSN 1664-705X (online)

Working Paper No. 309

\title{
Born to be an Entrepreneur? \\ How Cultural Origin Affects Entrepreneurship
}

Katharina Erhardt and Simon Haenni

December 2018 


\title{
Born to be an Entrepreneur? How Cultural Origin Affects Entrepreneurship*
}

\author{
Katharina Erhardt ${ }^{\dagger} \quad$ Simon Haenni ${ }^{\ddagger}$
}

December 11, 2018

\begin{abstract}
Persistent differences in entrepreneurial activity between regions and countries remain unexplained. This paper argues that cultural heritage is an important determinant. We exploit a quasi-experimental setting comparing entrepreneurial activities of individuals with different cultural ancestry from within Switzerland but who live in the same municipality today and are hence exposed to the same economic and institutional environment. We find that individuals with cultural origin on the German-speaking side of the Swiss language border found $20 \%$ more firms than their counterparts with cultural origin on the French-speaking side - no matter if they currently live in the German-speaking or French-speaking region. These newly founded firms are identical in terms of survival rate, industry composition, legal form, and firm size, independent of the cultural origin of firm founders. A model of entrepreneurial choice suggests that the empirical patterns of firm entry and performance are more likely driven by differences in risk aversion or preferences for entrepreneurship rather than by skill.
\end{abstract}

Keywords: Culture, Entrepreneurship, Natural experiment

JEL Classifications: D22, L26, Z10

\footnotetext{
* Acknowledgments: We are grateful for helpful comments and suggestions by Adrian Bruhin, Jayson Danton, Peter Egger, Beatrix Eugster, Andrea Ichino, Lingqing Jiang, Andrea Lassmann, Raphael Parchet, David Staubli, Josef Zweimüller, as well as seminar participants at the University of Zurich, ETH Zurich, and the University of Lausanne. We appreciate comments by the participants of the SSES Annual Congress 2017 and the 4 th ZEW Conference on the Dynamics of Entrepreneurship.

$\dagger$ ETH Zürich, Department of Management, Technology, and Economics, Leonhardstrasse 21, 8092 Zurich, Switzerland; E-mail: erhardt@kof.ethz.ch

$\ddagger$ University of Zurich, Department of Economics, Schoenberggasse 1, 8001 Zurich, Switzerland; E-mail: simon.haenni.ch@gmail.com
} 


\section{Introduction}

To bring Europe back to growth and create new jobs, we need more entrepreneurs.

Preamble of the Entrepreneurship 2020 Action Plan

European Commission

Not only in the European Union but all over the globe policy makers identify entrepreneurial activity as a crucial driver of economic outcomes such as innovation, job creation, economic growth, and development (e.g. Parker, 2004; Audretsch et al., 2006). In line with this assessment, research on the determinants of entrepreneurship is vast: Entrepreneurial activity has been shown to be correlated with per capita income, technological progress, and many different institutional factors such as labor market regulations, education and tax incentive schemes. Still, these factors can only explain a surprisingly small part of entrepreneurial activity: Even countries that are very similar in the aforementioned dimensions tend to exhibit persistent differences in their level of entrepreneurial activity. (Audretsch et al., 2007)

These unexplained differences in entrepreneurial activity across countries have for a long time been (often informally) attributed to an additional dimension - an 'entrepreneurial culture' - that co-determines the extent of entrepreneurial activity in a country (e.g. Weber, 1905; Hoselitz, 1957; Leff, 1979). However, from an empirical perspective identifying and quantifying the concept of 'entrepreneurial culture' has turned out to be challenging. Ideally, to answer the question on the role of culture in entrepreneurship, we would want to randomly assign people with different cultural background to the very same environment and assess the observed differences in their entrepreneurial activity.

In this paper, we use a quasi-experimental setting of that very flavour by exploiting two unique features of institutions in Switzerland. The first feature 
is the concept of place of origin which is recorded for every Swiss citizen in lieu of the place of birth that is recorded in most other countries. The place of origin is the municipality where ancestors had the right to common goods, is passed on over generations through the paternal line, and has been unchanged for centuries, no matter where a person lives today.

The second Swiss peculiarity that helps us assigning different places of origin to different cultures is the Swiss language border. The Swiss language border provides a unique empirical opportunity to identify cultural effects for three reasons. First, the Swiss language border is also a cultural border where values and norms diverge. ${ }^{1}$ These cultural differences become evident, for instance, when contrasting election and vote results at the Swiss language border. We show that this is also true for those votes that concern entrepreneurship. Second, the mainly spoken language changes sharply at the language border: within a distance of just a few kilometers the share of native French and German language speakers changes from more than 90 percent to less than 10 percent, respectively. Third, at the same time, the language border largely runs within cantons (states), holding laws and institutions constant on both sides. (e.g. Eugster et al., 2011, 2017; Eugster and Parchet, 2018)

In order to measure entrepreneurial activity, we make use of a comprehensive dataset on the universe of firms founded in Switzerland over the years 2002 2016. Specifically, these data provide information on the place of origin as well as on the place of residence of the firm founders. We complement the data with information on the overall distribution of residents in each Swiss municipality across places of origin as well as with the respective nearest distances of these places of origin to the language border. In the spirit of the ideal experiment outlined above, we contrast the entrepreneurial activity of potential founders that are exposed to the very same economic environment - hence, people living

\footnotetext{
${ }^{1}$ Unlike Chen (2013) we do not claim to separate language from culture but consider language as a component of culture that can serve as proxy for it.
} 
in the same municipality - but have their cultural origin just on different sides of the language border in a spatial regression discontinuity design. ${ }^{2}$ While we focus on firm founders with cultural origin around the language border, the municipalities of residence considered in the analysis are all municipalities of Switzerland. $^{3}$

We find that - within the same municipality of residence - individuals with cultural origin on the German-speaking side of the Swiss language border found $20 \%$ more firms than their counterparts with cultural origin on the Frenchspeaking side - no matter if they currently live in the German-speaking or the French-speaking region. We find identical results when focusing on firm founders whose first names suggest high cultural assimilation with the current region of residence. Furthermore, the cultural effect is observed separately at all three geographically not connected within-canton language borders. At the same time, these newly founded firms are shown to be identical in terms of survival rate, industry composition, legal form, and firm size, independent of the cultural origin of firm founders.

We rationalize these findings in a theoretical model of entrepreneurial choice that allows for three commonly discussed individual determinants of entrepreneurship: risk aversion, entrepreneurial skill, and sheer preference for entrepreneurship. In our model, individuals decide whether to become regular workers, obtaining a risk-free income, or to become entrepreneurs, obtaining a risky profit that is increasing in individual entrepreneurial abilities. The model reveals that the results found in the paper, namely the observation of higher firm foundation rates for individuals with German-speaking origin combined with identical measures of entrepreneurial success across founders with different cultural origin, can

\footnotetext{
${ }^{2}$ We focus on male firm founders, as past literature has shown strong gender differences between cultures with respect to labor force participation in general, and entrepreneurship in specific (Fernandez and Fogli, 2009; Alesina and Giuliano, 2010; Alesina et al., 2013), and because our measure for cultural origin is noisy for women due to the patriarchal inheritance rules related to said measure.

${ }^{3}$ As shown in Appendix Tables 12 and 13 the regression sample is largely representative for the universe of all firms.
} 
be explained by either differences in risk aversion or differences in preferences for being self-employed but not by differences in skills alone. These results are supported by survey data on personality traits across these two cultural areas which point towards risk aversion as being the dominant factor.

Magnitude and significance of the cultural component in entrepreneurial activity suggest an important role for culture in the economic development of Switzerland. Specifically, the differences in net entry rates account for around 128,000 additional jobs that have been created by entrepreneurs with Germanspeaking origin over the period of investigation, amounting to $2.5 \%$ of today's employment.

This paper contributes to an extensive literature on the role of culture in entrepreneurship. The idea of an entrepreneurial culture can be traced back at least to Weber's (1905) influential work on the protestant work ethic and its impact on entrepreneurial activity and modern capitalism. But the idea of an entrepreneurial culture has always been difficult to grasp empirically and many papers have faced challenges in identifying its impact on entrepreneurial activity, since culture and institutions often co-evolve (Benabou and Tirole, 2006; Alesina and Giuliano, 2015).

So far, correlational studies have suggested a relationship between different cultural components and entrepreneurial activity but causal evidence remains scarce (Guiso et al., 2006; Hayton et al., 2002; Stuetzer et al., 2016). Davidsson (1995) and Davidsson and Wiklund (1997) positively correlate regional differences in entrepreneurial values and beliefs with regional differences in new firm formation rates. Similarly, Obschonka et al. (2015) relate a personality-based measure of entrepreneurial culture to entrepreneurial activity and find that culture plays a key role in explaining regional differences in entrepreneurship. In a cross-country setting, Lassmann and Busch (2015) look at self-employment decisions of immigrants with different origins and find a positive correlation between self-employment rates in the immigrants' country of origin and their probability 
of being self-employed in the US. All these papers point out the importance of culture in entrepreneurship without providing a causal analysis.

In contrast, Glaeser et al. (2015) show suggestive reduced form evidence that hints to the existence of a regional entrepreneurial culture by using spatial locations of past mines as instrument. Stuetzer et al. (2016) use a similar historical instrument to explain regional differences in self-employment and regional differences of a measure for entrepreneurial culture without establishing a causal link between the two.

We contribute to this literature in three ways. First, we identify a causal effect of culture on entrepreneurship. Further, we use administrative data on firm registration and do not rely on survey evidence. Moreover, the firm-level data allows us to look at the life cycle of newly founded firms which gives us a measure for success and failure of entrepreneurial activity as well as various firm characteristics. Eventually, this additional information allows us to contrast different mechanisms that can explain the observed cultural differences.

More generally, we also contribute to the rapidly growing literature on cultural transmission of preferences and economic outcomes (see e.g. Nunn, 2009 for an overview of this literature). Past studies have examined the cultural persistence of differences in education, female labor force participation, preferences for redistribution, fertility rates, and living arrangements as well as the long-run economic growth effect of these determinants (Becker and Woessmann, 2009; Caicedo, 2018; Alesina et al., 2013; Luttmer and Singhal, 2011; Alesina and Giuliano, 2010; Fernandez and Fogli, 2009; Giuliano, 2007). A widelyused identification strategy in this literature relies on differences in outcomes of second-generation immigrants to the US or Europe. While this method credibly holds the environment at the country of residence constant, there are two potential drawbacks. First, children of immigrants are not a representative sample of their parents' country of origin and second, there might be unobserved non-cultural differences between children of immigrants with origin in different 
countries or regions of the world, due to diverse reasons for self-selection into migrating (Alesina and Giuliano, 2015).

In our setting, the environment of origin is very homogeneous, apart from the cultural component. We exploit only within-canton variation at the place of origin of ancestors, whose cultural background changes discontinuously at the language border. In other words, we compare individuals whose ancestors originate from the same canton and from within a few kilometers from each other but happened to live in different cultures. Thus, we can credibly exclude non-cultural factors like institutional, climatic, and geographic differences at the place of origin, while at the same time holding the current environment constant. Importantly, the identification in our setting does not stem from the subset of people whose ancestors have left their home, but we take into account the whole population including people who still live at their place of origin today.

Finally, we contribute to a historic debate among economists regarding the question on the nature of entrepreneurs and its cultural manifestation - most prominently by Knight (1921) and Schumpeter (1934). Knight (1921) underlines the role of risk bearing as one of the fundamental characteristics of an entrepreneur while Schumpeter (1934) emphasizes the innovative capacity and quality of the entrepreneur. Translated into economic models, Lucas Jr (1978) considers a model where the more able agents become entrepreneurs while Kihlstrom and Laffont (1979) provide us with a model of risk averse agents with the least risk averse becoming the entrepreneurs. We show that the results found in our paper can be rationalized in a model of risk aversion in the spirit of Knight (1921) and Kihlstrom and Laffont (1979) but not in a model of skill as put forward by Schumpeter (1934) and Lucas Jr (1978). 


\section{Cultural Background}

\subsection{Language Regions and Language Border}

Switzerland provides an ideal setting to study the effect of culture on entrepreneurship. Spanning the intersection of Germanic and Romance Europe, Switzerland comprises multiple linguistic and cultural regions within an otherwise very homogeneous environment. Historically, the Swiss multilinguality has its origins in the late antiquity when Alemannic groups immigrated into previous Latin regions. Since the middle ages language regions within current Swiss territory stayed remarkably stable (Lüdi, 2013). Figure 1 shows the distribution of official languages across the country.

The Swiss-German/Swiss-French language border is of particular interest in our context. First, it comprises the two main language regions of Switzerland accounting for $86 \%$ of the total population (Swiss Federal Statistical Office, 2014). Second, the Swiss-German/Swiss-French language border runs within cantons and even municipalities thereby providing a very sharp spatial separation of the language regions while institutions remain the same. To see this, note that most institutions and policies are set at the cantonal level, especially, in the historical context that we will exploit later on. Third, the Swiss-German/Swiss-French language border does not follow main geographical barriers. On these grounds, we will focus on the Swiss-German/Swiss-French language border and in particular, on the three bilingual cantons Bern, Fribourg, and Valais, i.e. on the parts of the language border that run within, rather than between cantons in subsequent analyses. These three bilingual cantons are marked with a bold line in Figure 1.

In all three cantons the mainly spoken language changes sharply at the language border. Figure 2 shows local polynomial regressions of this language discontinuity. For municipalities in the French-speaking region, shortest road distances to the language border are coded negatively while for municipalities 


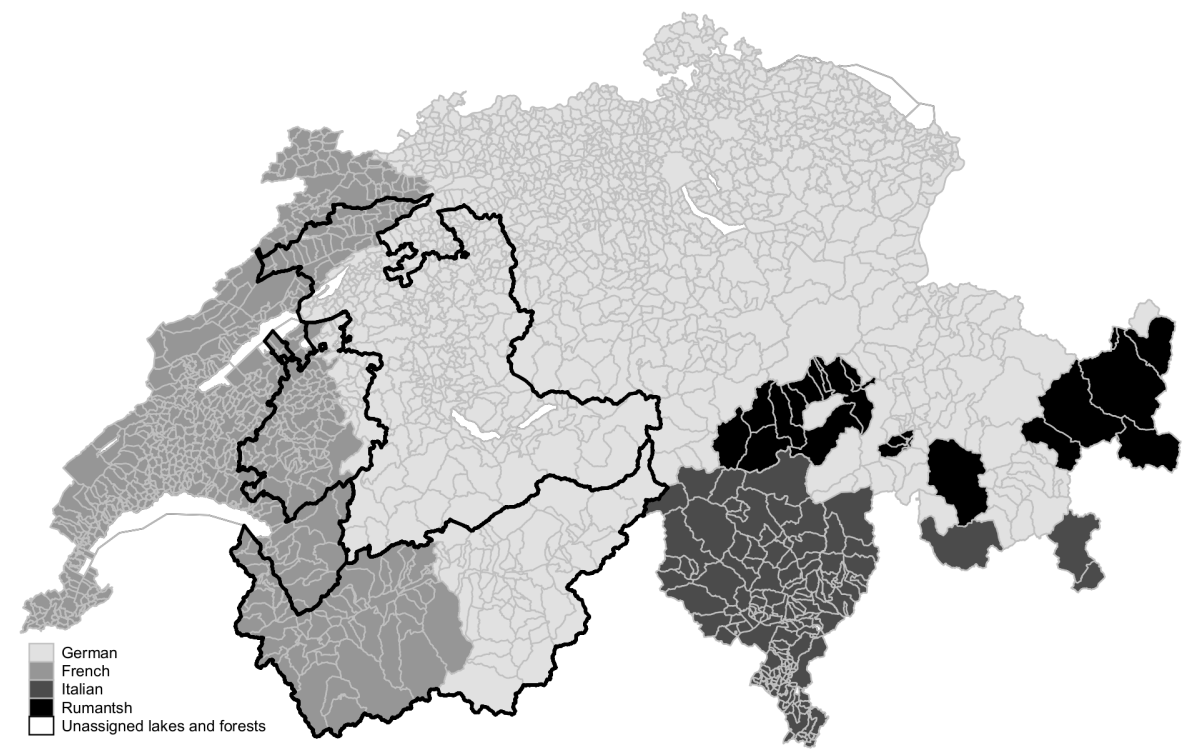

Municipalities coded by majority language. Borders of bilingual cantons are marked in bold. Data Source: Federal Statistical Office and Federal Office of Topography.

in the German-speaking region road distances are positive. ${ }^{4}$ Within just a few kilometers the share of French-speakers drops from more than $90 \%$ to below $10 \%$ and vice versa for German-speakers.

The Swiss-German/Swiss-French language border does not only separate the mainly spoken language but also defines two distinct cultural groups with different norms, values, and preferences. Swiss citizens experience these differences firsthand when comparing results of elections and votes whose outcomes typically strongly diverge at the language border. But also past research has exploited this setting to study the role of culture on various economic outcomes. Eugster and Parchet (2018) show evidence on cultural differences with respect to the desired role of the state: While voters in French-speaking regions regularly favor high

\footnotetext{
${ }^{4}$ Municipalities are coded as French- and German-speaking based on the major first language spoken in the municipalities according to the 2000 Census by the Swiss Statistical Office. Shortest road distances to the language border have been calculated as the shortest distance between a municipality center and the closest municipality center on the other side of the language border. Road distance data between municipalities are taken from search.ch and have been kindly provided by Eugster and Parchet (2018). Slightly different methods for calculating road distances have been used in the literature. In our setting, employing different methods does not affect the results.
} 
Figure 2: Main LANGUAGe as FunCtion of RoAd Distance to the LANGUAGE BORDER.

(a) Share of French SPEAKers

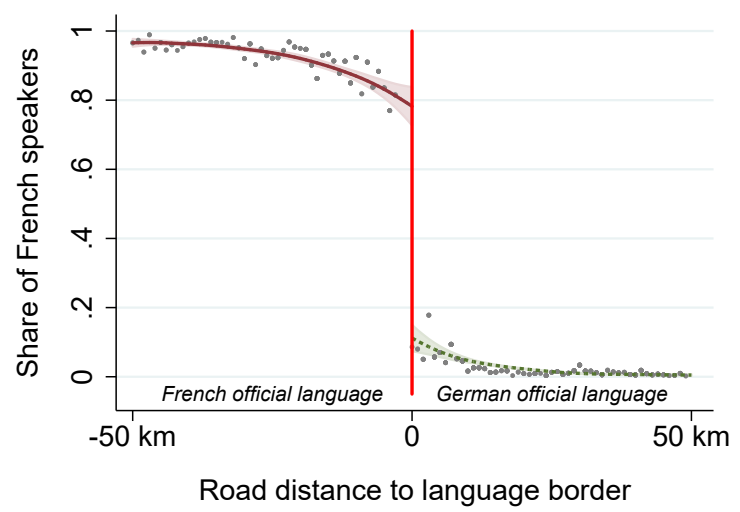

(B) Share of German speakers

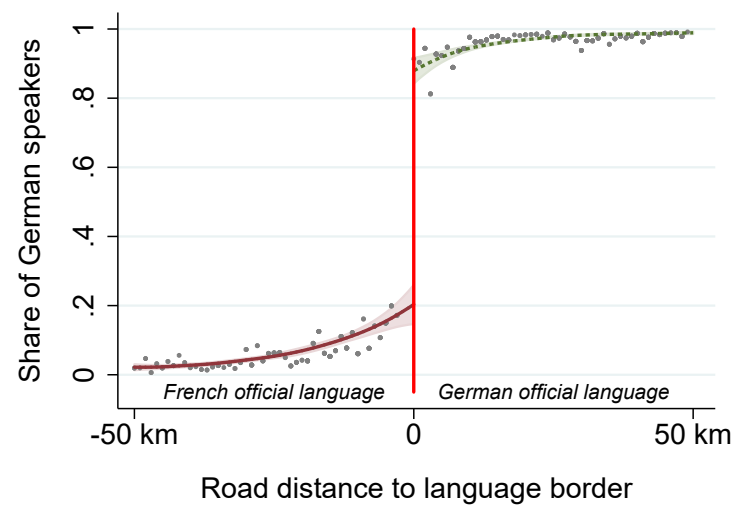

Share of Swiss population speaking French (a) and German (b) as their first Language as a function of the road distance to the language border. Estimates from local linear regressions, along with $95 \%$ confidence intervals and scatters representing population weighted $1 \mathrm{~km}$ averages.

taxes and large government involvement, German-speaking voters rather favor low taxes, a slim state, and strong individual responsibilities. Further studies focus on the role of culture on unemployment (Eugster et al., 2017), on the demand for social insurance (Eugster et al., 2011), or on financial literacy (Brown et al., 2018).

\subsection{First Evidence on Distinct Entrepreneurial Cultures}

Büchi (2003) argues that with respect to entrepreneurship the cultural divide at the language border began to manifest itself as early as the $19^{\text {th }}$ century. Also today, stylized facts suggest that the attitudes towards entrepreneurship vary across cultural regions in Switzerland: The direct democracy in Switzerland allows voters to voice their opinion in numerous federal referenda every year, among those some votes directly revealing their preferences for entrepreneurship. We analyze 246 federal referenda between 1981 and 2017 for which the leading 
Figure 3: Voting in Line with Swiss Federation of Small and Medium Enterprises.

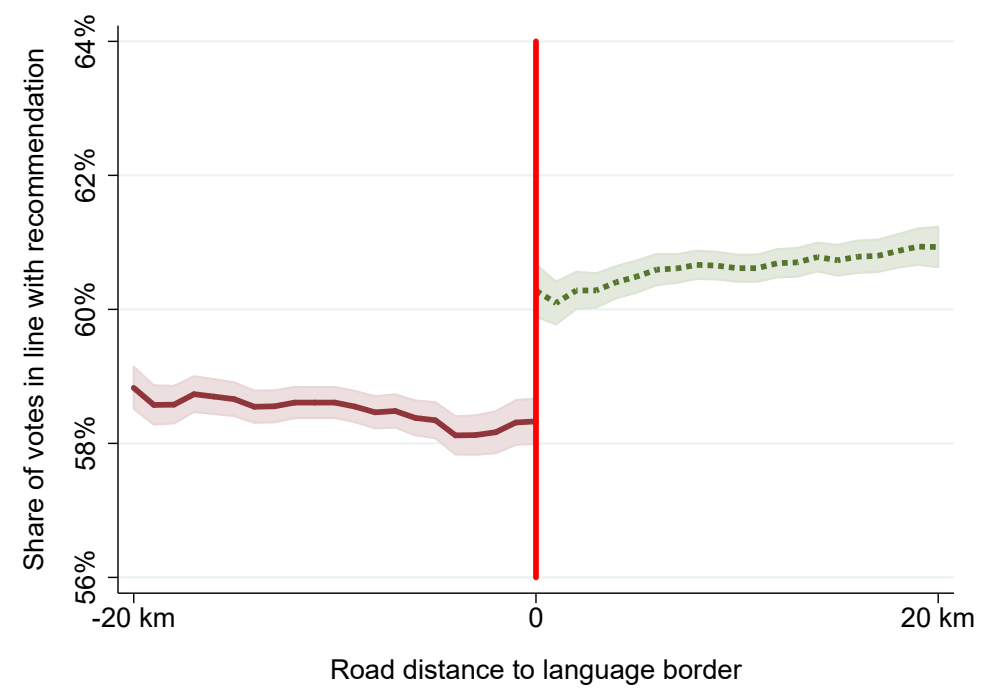

Share of population voting in line with recommendation by the Swiss Federation of Small and Medium Enterprises in 246 federal referenda between 1981 and 2017 . Lines represent $10 \mathrm{~km}$ moving averages (along with 95\% confidence intervals). Negative distances are municipalities in French-speaking regions while positive distances are municipalities German-speaking regions.

umbrella organization of Swiss Firms, the Swiss Federation of Small and Medium Enterprises $(s g v)^{5}$ issued an endorsement (source: swissvotes.ch).

We exploit the setting at the Swiss language border within the three bilingual cantons and contrast electoral support for $s g v$ in referenda by municipalities on both sides of the language border. Figure 3 shows the analysis thereby relying on the same distance coding that was described in the previous section. Crossing the language border from the French-speaking to the German-speaking region we observe a discrete increase of about $2 \%$-points in favor of the position endorsed by the $s g v$.

While this analysis provides some first suggestive evidence that the attitude towards entrepreneurial activities is different in the German-speaking region compared to the French-speaking region, an analysis of this kind is not well suited for causal identification. Specifically, knowing that cultural differences at

\footnotetext{
${ }^{5}$ The $s g v$ represents the majority of all Swiss Enterprises and is politically independent. The goal of the federation is to improve the economic and political environment for enterprises. They cover a wide range of topics like education, labor market, taxes, and environmental issues.
} 
the language border can potentially also affect the entrepreneurial environment such as demand factors or tax incentives, this type of analysis does not allow for disentangling cultural origin from the immediate environment of potential entrepreneurs.

To tackle this identification challenge, we introduce a novel measure of cultural origin beyond the current place of residence in the subsequent section. This measure allows us to contrast different cultural backgrounds of entrepreneurs while at the same time holding constant the immediate environment of these entrepreneurs.

\subsection{Place of Origin}

Swiss citizens do not only have a national citizenship but also a municipal citizenship, formally called place of origin. The place of origin is the place where an individual's ancestors are from and is passed on from generation to generation through the paternal line. ${ }^{6}$ Married women often have two places of origin: one obtained from their father and one obtained from their husband (Swiss Confederation, 2013). ${ }^{7}$

The concept of the place of origin has its roots in the $18^{\text {th }}$ century. Back then, established citizens did not want to share common goods with new residents, which led to a separation of the place of origin and place of residence. Until the revision of the constitution in 1874 even political rights were linked to the place of origin, rather than the place of residence. During the course of the $19^{\text {th }}$ and $20^{\text {th }}$ century the place of origin gradually lost all its competences to the place of residence as more and more people started to move away from their ancestors'

\footnotetext{
${ }^{6}$ Only since 2013 parents can choose whether the child receives a mothers or fathers place of origin.

${ }^{7}$ In principal, it is possible to become naturalized at the current place of residence, after having lived there for several years. However, doing so is costly and has purely symbolic value. Indeed, very few citizens take advantage of this possibility: E.g. in Zurich - the largest Swiss municipality - only 1/626 Swiss citizens with place of origin outside of Zurich chooses to get naturalized each year. In case a Swiss citizens obtains a second place of origin, we rely on the original place of origin that was inherited.
} 
place of origin (Schweizer, 2011). While in $186059 \%$ of Swiss citizens lived at their place of origin this share decreased to $34 \%$ until 1910 (Christ, 2006).

But until today, the concept of the place of origin remains and it is still mentioned in official documents, like passports, and official registries, instead of the place of birth. Even though the place of origin is largely irrelevant in dayto-day life, for many citizens the concept has sentimental value: It is the place where the ancestors are from and roots of family names can often be traced back to the place of origin (Britt, 2013). So far all legislation trying to abandon the concept failed and even municipalities that do no longer exist due to municipality mergers often remain 'existent' as place of origin and are passed on to the next generation (Swiss Confederation, 2018).

Using a novel data set provided by the Swiss Federal Statistical Office, we know the exact composition of the places of origin of the residents of any Swiss municipality in 2016. Figure 4 exemplary shows the distribution of places of origin for three major cities: Fribourg is located right on the language border, Lausanne is located in the French-speaking region, and Zurich is located in the German-speaking region. We see that in all three cities individuals have their place of origin in all parts of the country, but in a gravity-like pattern the density decreases with distance to the place of residence. In the median municipality, only $14 \%$ of its residents have their cultural origin in this very municipality. Typically, the share is higher for bigger municipalities.

In our setting the place of origin provides an ideal measure for the origin of the family of an entrepreneur that is not affected by today's policies and institutions. In combination with the place of residence it allows us to disentangle cultural origin from current environmental influences. We discuss the role of cultural origin in our identification strategy in more detail in section 4.1. 
Figure 4: SHARE OF INDIVIDUALS FROM EACH PLACE OF ORIGIN LIVING IN THREE MAJOR CITIES.

(A) Fribourg

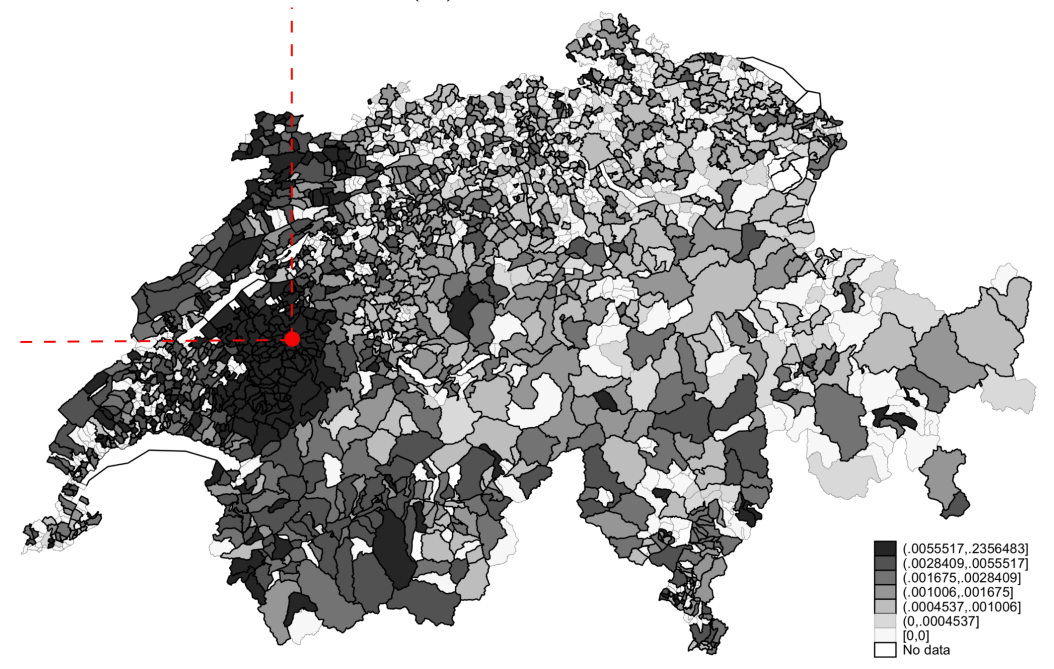

(B) Lausanne

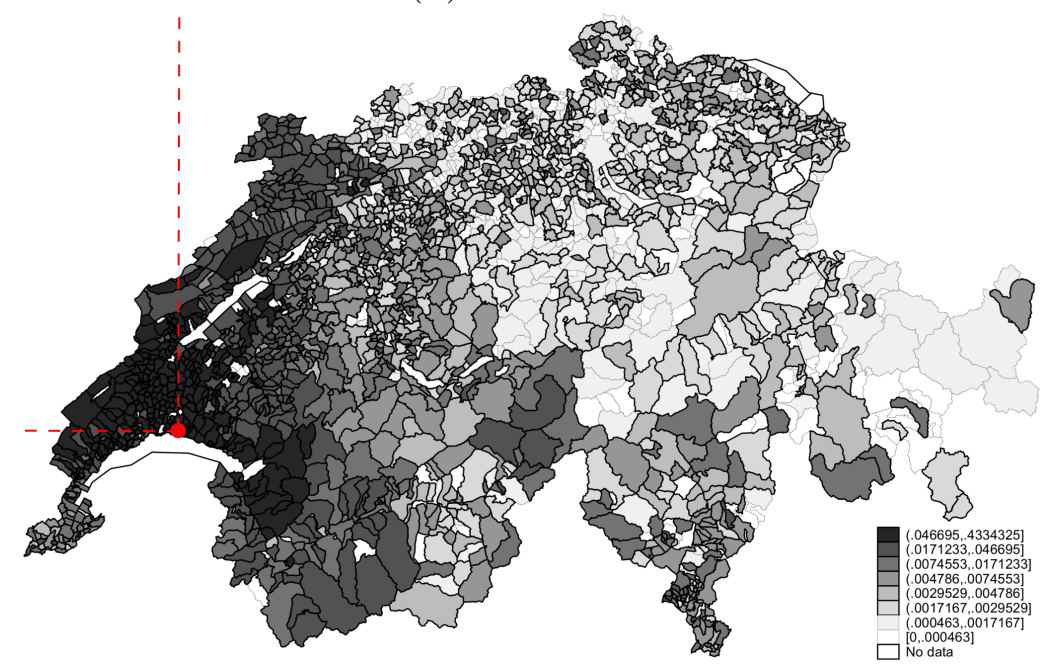

(c) ZURICH

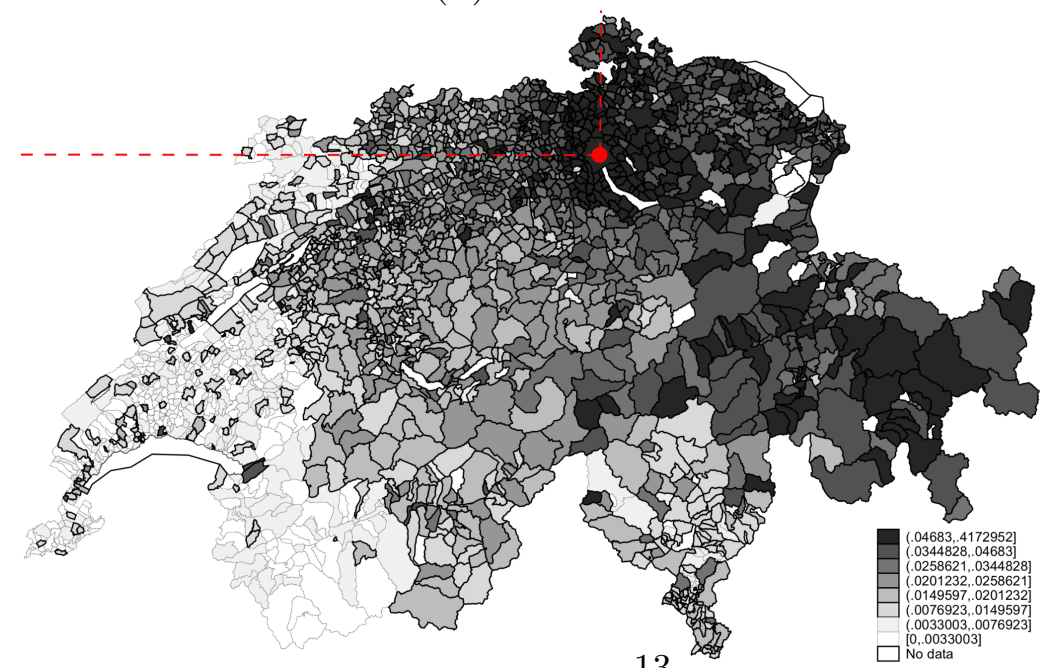

Share of individuals from each place of origin living in three major cities (Fribourg, Lausanne, and Zurich). Darker colors indicate higher population shares from a certain place of origin living in the respective cities. 


\section{Data}

\subsection{Data Set}

Our main data source are all 26 cantonal commercial registers in Switzerland.

These registers cover the universe of newly registered firms between January 2002 and December 2016. Reported information includes company registration and deregistration dates, reason for deregistration, place of business, legal structure of the company, and some information about the founders, such as name, gender, place of residence, and place of origin. For the empirical analysis we focus on profit-oriented firms and exclude public corporations, nonprofit associations, and foundations. If several founders are listed, we consider the person listed first in official documents as the founder. ${ }^{8}$

We focus on firm founders with place of origin within $50 \mathrm{~km}$ from the language border in the three bilingual cantons Bern, Fribourg, and Valais. ${ }^{9}$ Today's places of residence of these founders are, however, all over Switzerland. Throughout the analysis, we focus on male firm founders for two main reasons. First, until recently, women were required to adapt the place of origin of their husband. Second, there is evidence that attitudes towards female labor market participation differ across the different cultural regions of Switzerland (Steinhauer, 2013) and we want to avoid wrongly ascribing the effects we identify with different attitudes towards women that participate in the labor market.

We assign places of origin (indexed by $j$ ) to one of the two cultural areas, French-speaking and German-speaking, depending on the majority language according to the 2000 census (Federal Statistical Office, 2000). ${ }^{10}$ Of all places of origin that are within the $50 \mathrm{~km}$ distance window in the three bilingual can-

\footnotetext{
${ }^{8}$ Note that founders are not listed in alphabetical order but according to their role within the firm. Excluding firms with more than one founder does not change our results.

${ }^{9}$ Considering a $50 \mathrm{~km}$ window around the language border has become the standard in previous papers exploiting the setting at the Swiss language border (e.g. Eugster et al., 2011, 2017). We will, however, show the robustness of our results to choosing different distance windows in Table 4.

${ }^{10}$ Majority languages have remained largely unchanged since the middle ages (Lüdi, 2013).
} 
Table 1: Summary Statistics of the Firm Registry Data.

\begin{tabular}{lccccc}
\hline \multicolumn{1}{c}{ Variable } & Mean & SD & Min. & Max. & N \\
\hline Founding year & & & 2002 & 2016 & 40,193 \\
French-speaking origin & 0.357 & 0.479 & 0 & 1 & 40,193 \\
Distance to language border & 9.782 & 27.318 & -49.094 & 49.466 & 40,193 \\
Deregistration year & & & 2002 & 2016 & 10,496 \\
Deregistration & 0.261 & 0.439 & 0 & 1 & 40,193 \\
Liquid./Closure/Bankruptcy & 0.185 & 0.388 & 0 & 1 & 40,193 \\
Bankruptcy & 0.057 & 0.231 & 0 & 1 & 40,193 \\
\hline
\end{tabular}

tons, 231 municipalities are classified as French-speaking and 307 are classified as German-speaking. For every municipality we calculate the shortest distance to the language border, $D_{j} .{ }^{11}$ In French-speaking municipalities distances are coded negatively while in German-speaking municipalities distances are coded positively. Table 1 shows the summary statistics of the information extracted from the firm registries.

Using these registry data we can construct the total number of firms that are founded by people living in every Swiss municipality $i$ with place of origin in $j$ (that lies in canton $c$ ) in year $t, N_{i j c t}$. We match this information with a comprehensive data set on the number of residents in every Swiss municipality $i$ from each place of origin $j, P_{i j}$ (obtained from the Swiss Federal Statistical Office). Note that we focus on places of origin that are within $50 \mathrm{~km}$ of the language border and lie within the bilingual cantons of Bern, Valais or Fribourg. The municipalities of residence considered are, however, all municipalities in Switzerland.

Summary statistics of the respective data set are provided in Table 2. These summary statistics correspond to the sample of the baseline estimation in Table

\footnotetext{
${ }^{11}$ Shortest road distances to the language border have been calculated as the shortest distance between a municipality center and the closest municipality center on the other side of the language border. Road distance data between municipalities are taken from search.ch and have been kindly provided by Eugster and Parchet (2018). Slightly different methods for calculating road distances have been used in the literature. In our setting, employing different methods does not affect the results.
} 
Table 2: Summary Statistics of the Regression Sample.

\begin{tabular}{lcccc}
\hline \multicolumn{1}{c}{ Variable } & Mean & SD & Min. & Max. \\
\hline No of firms, $N_{i j c t}$ & 0.014 & 0.164 & 0 & 36 \\
French-speaking origin, $F_{j}$ & 0.302 & 0.459 & 0 & 1 \\
Log no of residents from $j$ in $i, \log \left(P_{i j}\right)$ & 1.039 & 1.019 & 0 & 9.308 \\
Distance to language border, $D_{j}$ & 12.783 & 25.497 & -49.094 & 49.466 \\
\hline \multicolumn{1}{c}{ No of observations } & \multicolumn{4}{c}{$2,696,955$} \\
\hline
\end{tabular}

3. Hence, all singletons that are captured by fixed effects are already dropped from this sample.

We complement these data with further information on the places of origin, such as the average educational background, main religion, and population size classes, as well as three official municipality classifications of the Swiss Federal Statistical Office that distinguish between three degrees of urbanization, three degrees of agglomeration, and 22 municipality types that define the sectoral specialization of these municipalities such as 'agrarian municipality' or 'touristic municipality'. ${ }^{12}$

\section{Cultural Differences in Firm Foundations}

\subsection{Identification Strategy}

In order to measure the effect of cultural origin on entrepreneurial activity we contrast the entrepreneurial activity of potential founders that are exposed to the very same economic environment - hence, Swiss citizens living in the same municipality - but have their cultural origin just on different sides of the language border in a spatial regression discontinuity design. The proposed strategy allows us to tackle two main identification challenges.

First, we want to separate cultural origin from the environment of firm founders. Therefore, we control for the environment of firm founders by absorb-

\footnotetext{
${ }^{12}$ These information are based on the 2000 Census conducted by the Swiss Federal Statistical Office.
} 
ing municipality-of-residence fixed effects, i.e. we compare firm founders with different places of origin but who live in the same municipality. Second, we want to ensure that our measure of cultural origin only picks up cultural differences. This is achieved by contrasting only individuals with place of origin in the same (bilingual) canton in a spatial regression discontinuity setting. Hence, we derive our cultural estimate by comparing firm founders who i) live in the same municipality, ii) with cultural origin in the same canton, but from different municipalities either just on the French-speaking or just on the German-speaking side of the language border. ${ }^{13}$

To illustrate better what is picked up by our measure of culture, let us consider an individual $s$ and his choice to become an entrepreneur, $P\left(\right.$ Entrepreneur $\left._{s}\right)$. The literature has identified a host of determinants entering this choice function that can be classified into determinants of the current environment $\left(a_{s}\right)$ and individual-level determinants. For our purpose, it is useful to further distinguish between non-cultural individual-level determinants $\left(b_{s}\right)$ and cultural individuallevel determinants $\left(c_{s}\right) \cdot{ }^{14}$ For the moment, let us abstract from the question of classification into these schemes and consider these factors as given.

Thus, we can express an individual's likelihood to become an entrepreneur as a function of three distinct factors $\left(a_{s}, b_{s}, c_{s}\right)$. To find the probability of $N$ events of entrepreneurship in a population of $P$ individuals, one divides $P$ into $n$ subintervals, $P_{1}, P_{2}, \ldots, P_{n}$, and approximates the answer as the binomial probability of observing $N$ successes in $n$ trials. For $n \rightarrow \infty$ we obtain the Poisson distribution (Cameron and Trivedi, 2013). Hence, the expected number of events of entrepreneurship for a population $m$ with exposure to $P_{m}$ people is

\footnotetext{
${ }^{13}$ We also include a handful of additional controls at the municipality of origin level. These controls absorb further potential heterogeneities like religion, size, or wealth of the municipality and help us to estimate the cultural effect more precisely. Note, however, that none of these controls is crucial for our findings, as is reported in the last column of robustness table 4 .

${ }^{14} \mathrm{We}$ acknowledge that the environment of the entrepreneur also consists of culturally determined components (Benabou and Tirole, 2006). However, since we will be able to perfectly account for this dimension later on, we can treat the environment-level components jointly in what follows.
} 


$$
\mathbb{E}\left[N_{m} \mid P_{m} ; a_{m}, b_{m}, c_{m}\right]=e^{\ln \left(P_{m}\right)+\beta_{0}+\beta_{a} a_{m}+\beta_{b} b_{m}+\beta_{c} c_{m}},
$$

where $\left(a_{m}, b_{m}, c_{m}\right)$ characterizes the distribution of individual determinants $\left(a_{s}, b_{s}, c_{s}\right)$ in population $m$. Any population in our data set is characterized by the tuple $m=\{i j c t\}$ indicating the municipality of residence, the municipality of origin, the canton of origin, and the respective year.

The aim of our analysis is to identify differences in the distribution of individual characteristics $\left(a_{s}, b_{s}, c_{s}\right)$ across populations that we consider to be of different cultural origin. Since cultural origin is identified by the language prevailing in the place of origin, it is crucial to explicitly take account of the role language played in shaping the distribution of places of origin within places of residence. Specifically the distribution of individual characteristics might be different in the subset of individuals that settled down far from their place of origin or possibly even in a different language region. Even though the establishment of a family in its current place of residence often took place many generations back, these specific characteristics could have been transmitted over generations and be correlated with entrepreneurial activity today. To emphasize that our results are not driven by first-generation residents, we will explicitly consider only firm founders who have a first name which is typical for their current place of residence in an additional specification.

In general, as becomes evident from Figure 4, the distribution of places of origins within a municipality of residence follows a gravity-like pattern and is largely determined by distance. These distance-related patterns are perfectly accounted for by implementing a spatial discontinuity design. ${ }^{15}$

\footnotetext{
${ }^{15}$ In a robustness check we additionally control for the distance between municipality of residence and place of origin, potentially capturing the composition of people migrating there. We will also account for the share of people of a place of origin $j$ living in municipality $i$ to capture any compositional effects related to the probability to migrate to some place.
} 
However, apart from distance, language differences also affect the current distribution of places of origin across municipalities. We will therefore explicitly account for the differences in individual characteristics that all populations share where the mainly spoken language in place of origin and municipality of residence differs by introducing an indicator variable $\zeta_{m}$. This indicator is assumed to be symmetric for both language regions: we allow for compositional differences in types of people who currently live in a different cultural environment compared to their place of origin but we assume that this compositional difference is the same independent of the direction of migration.

We validate this assumption by looking at the relationship between places of origin and places of residence in Table 10 in the Appendix. While both distance and a different main language spoken affect migration negatively, the latter estimate is identical for French and German-speaking places of origin.

Explicitly accounting for the indicator $\zeta_{m},(1)$ can be rewritten as

$$
\mathbb{E}\left[N_{m} \mid P_{m} ; a_{m}, b_{m}, c_{m} ; \zeta_{m}\right]=e^{\ln \left(P_{m}\right)+\beta_{0}+\beta_{a} \tilde{a}_{m}+\beta_{b} \tilde{b}_{m}+\beta_{c} \tilde{c}_{m}+\zeta_{m}}
$$

where $\left(\tilde{a}_{m}, \tilde{b}_{m}, \tilde{c}_{m}\right)$ characterizes the distribution of individual determinants $\left(a_{s}, b_{s}, c_{s}\right)$ in population $m$ controlling for differences coming from migration across the language border $\zeta_{m}$.

Now consider the citizens of a municipality $i$ at time $t$ with cultural origin from municipality $j$ that lies in canton $c$ and compare them to the citizens of the same municipality $i$ at time $t$ but with cultural origin from municipality $j^{\prime}$ that also lies in canton $c$. Municipality $j$ lies at $D_{j}>0$ while municipality $j^{\prime}$ lies at $D_{j^{\prime}}<0$. At $D=0$ the language border introduces a discrete change in the composition of mainly spoken language and the prevalent culture. Let us now compare how individual characteristics $\left(a_{s}, b_{s}, c_{s}\right)$ are distributed within the populations of $m=\{i j c t\}$ and $m^{\prime}=\left\{i j^{\prime} c t\right\}$ abstracting from any difference captured by $\zeta_{m}$. Without loss of generality, we focus on the first moment of the distribution and state our identification assumptions 


$$
\begin{aligned}
& \lim _{\epsilon \rightarrow 0} \mathbb{E}\left[a \mid s \in\left\{i j c t \mid D_{j}=0+\epsilon\right\} ; \zeta_{i j}\right]-\lim _{\epsilon \rightarrow 0} \mathbb{E}\left[a \mid s \in\left\{i j^{\prime} c t \mid D_{j^{\prime}}=0-\epsilon\right\} ; \zeta_{i j}\right]=0 \\
& \lim _{\epsilon \rightarrow 0} \mathbb{E}\left[b \mid s \in\left\{i j c t \mid D_{j}=0+\epsilon\right\} ; \zeta_{i j}\right]-\lim _{\epsilon \rightarrow 0} \mathbb{E}\left[b \mid s \in\left\{i j^{\prime} c t \mid D_{j^{\prime}}=0-\epsilon\right\} ; \zeta_{i j}\right]=0 \\
& \lim _{\epsilon \rightarrow 0} \mathbb{E}\left[c \mid s \in\left\{i j c t \mid D_{j}=0+\epsilon\right\} ; \zeta_{i j}\right]-\lim _{\epsilon \rightarrow 0} \mathbb{E}\left[c \mid s \in\left\{i j^{\prime} c t \mid D_{j^{\prime}}=0-\epsilon\right\} ; \zeta_{i j}\right]=\delta
\end{aligned}
$$

Hence, for identification of $\delta$ we require that the composition of all noncultural determinants of entrepreneurship is on average the same for any population of individuals living in the same municipality today and with cultural origins from the same canton but either directly to the left $\left(\lim _{\epsilon \rightarrow 0} D_{j^{\prime}}=0-\epsilon\right)$ or directly to the right from the language border $\left(\lim _{\epsilon \rightarrow 0} D_{j}=0+\epsilon\right)$.

Let us come back to the question of classification of potential determinants of entrepreneurship into the vectors $\left(a_{s}, b_{s}, c_{s}\right)$. It is straightforward to argue that municipality-specific components such as taxes and market size are captured in $a$ and are the same for individuals of population $m$ and $m^{\prime}$ that actually live in the same municipality today and can thus be captured by municipality-of-residence fixed effects.

In order to highlight the differences between non-cultural and cultural components, $b$ and $c$, more clearly, consider the example of education. ${ }^{16}$ Schooling has been mandatory and free-of-charge for all children since the mid of the $19^{\text {th }}$ century in all of Switzerland. Additionally, the ancestors of the persons in $m$ and $m^{\prime}$ were exposed to the same educational environment because their ancestors are from the same canton that provides the education system. Thus, if the educational composition of $m$ and $m^{\prime}$ were entirely driven by the provision of access to education, there should not be any differences in the two groups. However, if one of the two cultural groups valued education more than the other, we would

\footnotetext{
${ }^{16}$ One customary definition prevailing in the economic literature considers culture to be 'those customary beliefs and values that ethnic, religious, and social groups transmit fairly unchanged from generation to generation' (Guiso et al., 2006).
} 
expect education levels to differ between the two groups, but for cultural reasons and hence being captured in $c .^{17}$

This separation is at the heart of our identification strategy and relies on the spatial RDD at the place of origin within cantons accounting for all components of $b$. In plain words, we consider that any effect that is estimated in this specific spatial RDD setting to be driven by cultural origin alone. Not only is this assumption credible in the specific context exploited in this paper and described in detail in section 2 , we can also provide convincing plausibility checks. Specifically, we will estimate the spatial RDD separately for each of the three cantons in our sample. As becomes evident from Figure 1 the language borders of these cantons are geographically not connected and up to $200 \mathrm{~km}$ apart from each other. The only common characteristic of these three language borders is the separation of the German-speaking and the French-speaking culture. ${ }^{18}$ Any effect that is identified at the language border in any of these three cantons separately can in all conscience be attributed to culture.

So far, we remain silent on what exactly the cultural determinants are, but it is reasonable to think of them as a composite of potentially many elements. We will shed more light on the nature of this composite in section 6 .

\subsection{Estimation}

In order to measure the effect of cultural origin on new firm foundations we look at the number of new firms founded by individuals with origin in municipality

\footnotetext{
${ }^{17}$ Note that results are not sensitive to controlling for average education levels at the place of origin.

${ }^{18}$ In Appendix A.2 we show additionally that place of origin characteristics are balanced at the language border.
} 
$j$ and canton $c$ who live in municipality $i$ in year $t\left(N_{i j c t}\right)$. We estimate the following Poisson regression model,

$$
\begin{gathered}
N_{i j c t}=\mathbb{E}\left[\operatorname { e x p } \left[\alpha_{i}+\kappa_{c}+\sigma_{t}+\delta F_{j}+\gamma \ln \left(P_{i j}\right)+\zeta D_{j}+\eta F_{j} \times D_{j}\right.\right. \\
\left.\left.+\beta X_{j}+\lambda Z_{i j}\right]\right],
\end{gathered}
$$

where $\delta$ is the main coefficient of interest, capturing the effect of French-speaking origin $\left(F_{j}\right) . P_{i j}$ is the exposure variable, controlling for the population at risk to become an entrepreneur. $D_{j}$ and the interaction $F_{j} \times D_{j}$ control for the shortest distance from the place of origin to the language border. These variables will account for the continuous change in composition of the population in terms of their cultural heritage as we move away from the language border. $X_{j}$ denotes a vector of control variables at the level of the place of origin ${ }^{19}$ and $Z_{i j}$ captures variables that control for the compositional differences of the population from $j$ in $i$. Further, regressions absorb municipality fixed effects for places of residence $\left(\alpha_{i}\right)$, canton fixed effects for places of origin $\left(\kappa_{c}\right)$, and year fixed effects $\left(\sigma_{t}\right){ }^{20}$ Standard errors are heteroskedasticity-robust and clustered at the municipality of residence.

\subsection{Results}

We show the main results of estimating equation 6 in Table 3. Column (i) shows the baseline regression while Columns (ii) and (iii) control for compositional differences by including the $(\log )$ distance between place of origin and place of residence and by accounting for the share of municipal residents of $j$ living in municipality $i$, respectively. The coefficient of primary interest on French ${ }_{j}$ is

\footnotetext{
${ }^{19}$ These controls absorb further potential heterogeneities like religion, size, or economic specialization of the municipality and help us to estimate the cultural effect more precisely. Note, however, that none of these controls is crucial for our findings, as is reported in the last column of robustness table 4 .

${ }^{20}$ Absorbing municipality of residence $\times$ year fixed effects instead leads to virtually identical results. The respective regression in presented in Table 11 in the Appendix.
} 


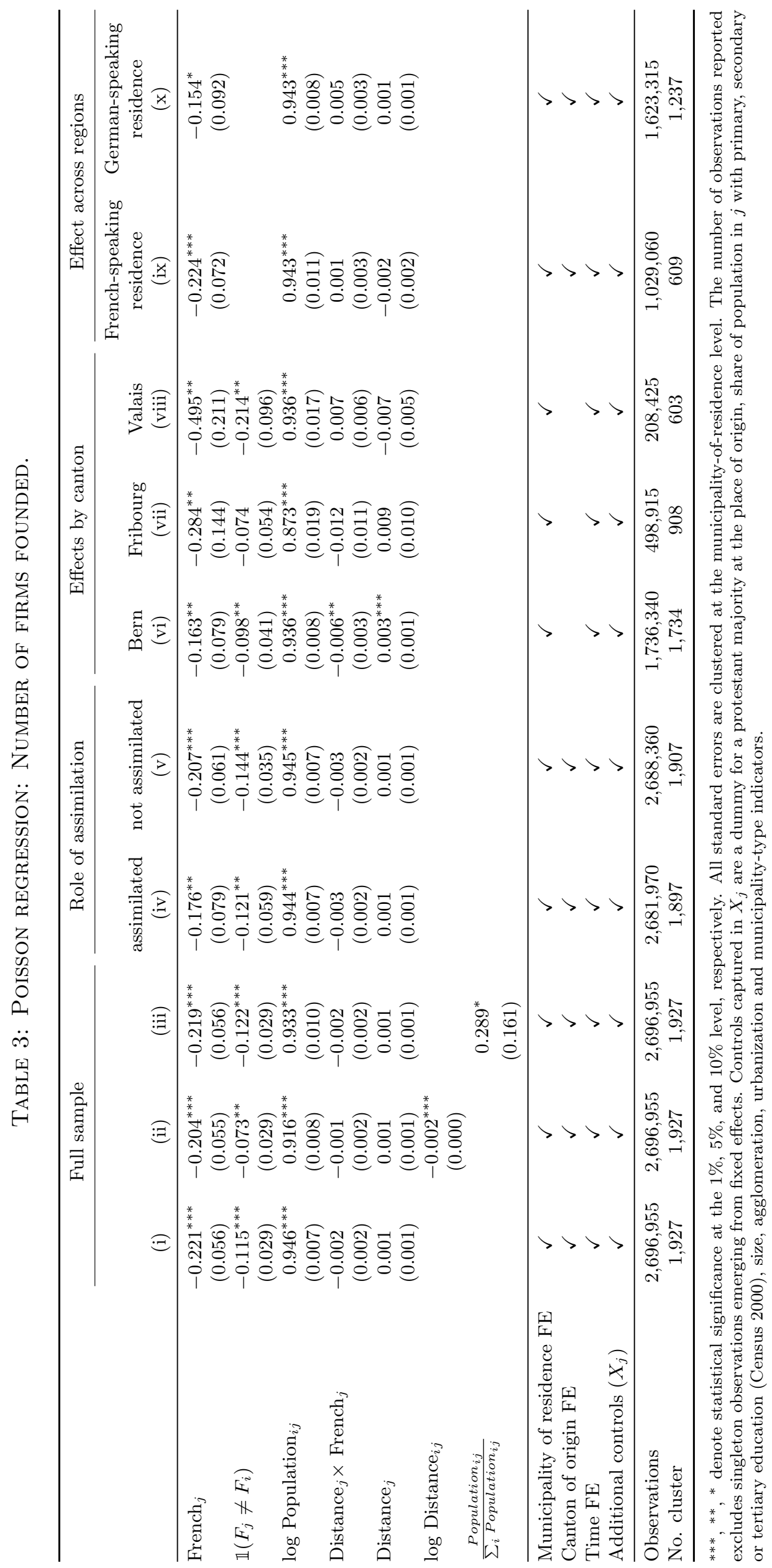


almost identical in columns (i)-(iii) and suggests that persons with cultural origin on the French side of the language border found $1-\exp (-0.22) \approx 20 \%$ fewer firms than persons with a cultural origin on the German side of the language border.

The indicator variable $\mathbb{1}\left(F_{j} \neq F_{i}\right)$ that accounts for the effect of living in a municipality that lies in a different language region than the place of origin enters negatively. The same sign is found for the distance between place of origin and place of residence, $\log$ Distance $_{i j}$. Moreover, the higher the share of municipal residents living in a municipality, the more firms are founded. These findings could be explained, e.g., by the role of social networks for firm founders which might be stronger the closer people live to their place of origin. However, accounting for these compositional differences does not affect the coefficient of interest and hence, can not explain the strong effect effect of cultural origin on firm foundations.

The $\log$ number of residents from $j$ living in $i$ denotes the exposure variable and is expected to be one if the number of firms founded by people from $j$ in $i$ is perfectly proportional to the population of people from $j$ in $i$. While the estimated coefficient is statistically different from one it is very close to one, suggesting a close-to-proportional relationship. ${ }^{21}$ The coefficients estimated on the two measures of distance to the language border are small and not statistically significant.

So far, the place of origin has not revealed when people have left their cultural origin. In order to investigate if the results persist also for those entrepreneurs whose families have likely been already well assimilated in the current cultural region, we use the first names of firm founders and categorize them as typical names of the language region of the place of residence. ${ }^{22}$ The estimates on

\footnotetext{
${ }^{21}$ In a robustness check reported in the Table 4 , we treat $\ln \left(P_{i j}\right)$ as a classical exposure variable and fix its coefficient to be one. All results stay the same.

${ }^{22}$ Specifically, we take the 100 most frequent names of all German- and French-speaking Swiss citizens and ignore any names that are common in both language regions. Based on this classification, we classify entrepreneurs with a German name living in the German-speaking
} 
French cultural origin in the two sub samples of assimilated entrepreneurs in column (iv) and non-assimilated entrepreneurs in column (v) are statistically not distinguishable and suggest that the effect of cultural origin is not driven by entrepreneurs that only recently moved to their current municipality of residence. Moreover, this analysis provides evidence against the claim that communication barriers may be driving the results.

Furthermore, columns (vi) - (viii) show baseline estimates for each canton of origin separately by estimating the spatial regression discontinuity for people with place of origin around each of the three geographically separated segments of the language border. Even though sample sizes are reduced considerably, all three estimates of cultural origin are individually significant and of similar magnitude. These results reassure that the estimated effect is indeed attributable to cultural origin.

Finally, to argue that our estimates are not driven by differences rooted in the language region of the municipalities of residence, we estimate the model separately for people living in the French and the German language region in columns (ix) and (x), respectively. Importantly, we find that individuals with cultural background from the French-speaking side of the language border found fewer firms than individuals with cultural background from the German-speaking side, no matter in which language region they live today. The estimated coefficients in column (ix) and (x) are within one standard deviation from one another.

region but with French-speaking place of origin and entrepreneurs with a French name living in the French-speaking region but with German-speaking place of origin as assimilated and compare them with the native population in Column (iv). In contrast, in column (v) we classify entrepreneurs with a non-German name living in the German-speaking region but with French-speaking place of origin and entrepreneurs with a non-French name living in the Frenchspeaking region but with German-speaking place of origin as not assimilated and compare them with the native population. In order to correct the exposure variable log Population $_{i j}$, we adjust the number by the share of the respective names in the sample of people with French-speaking origin living in the German-speaking region and the sample of people with German-speaking origin living in the French-speaking region, respectively. Since the coefficient estimated on the exposure variable is very close to the specifications of the full sample, the adjustment seems to perform well. 


\subsection{Robustness}

In order to assess the sensitivity of our results, we conduct various robustness checks which we report in Table 4. Columns (i)-(iii) report estimated coefficients when constraining the distance of municipalities of origin to the language border from $50 \mathrm{~km}$ in the baseline to $20 \mathrm{~km}, 30 \mathrm{~km}$, and $40 \mathrm{~km}$, respectively. We see that the coefficients are virtually identical across all specifications and stay significant at conventional levels even though the sample size is reduced considerably.

In Column (iv), we omit any distance controls. We can think of this specification as estimating an average treatment effect of culture as treatment variable rather than a local average treatment effect as estimated by the spatial RDD. Results are the same.

We also consider the sensitivity of our results to functional form assumptions in Columns (v)-(vii). First, instead of a Poisson regression, we estimate a negative binomial regression which is a standard alternative to Poisson in models of count data. Second, we estimate a Poisson regression as in the baseline but fix the exposure variable log Population $_{i j}$ to enter with a coefficient of one. Third, we allow for a zero-inflated Poisson regression to take account of the high number of zeros in our data set with the inflation process being a function of the municipality of origin size and the municipality of residence size. The estimated coefficients in Columns (v)-(vii) are nearly identical to the baseline regression result.

Furthermore, we exclude the bilingual places of origin, Fribourg and Bienne, from our data set in Column (viii), consider only municipalities of residence within $50 \mathrm{~km}$ of the language border in Column (ix), and rerun the main specification without control variables at the level of the place of origin in Column (x). None of the estimated coefficients of these robustness exercises turns out to be notably different from our baseline coefficient. 


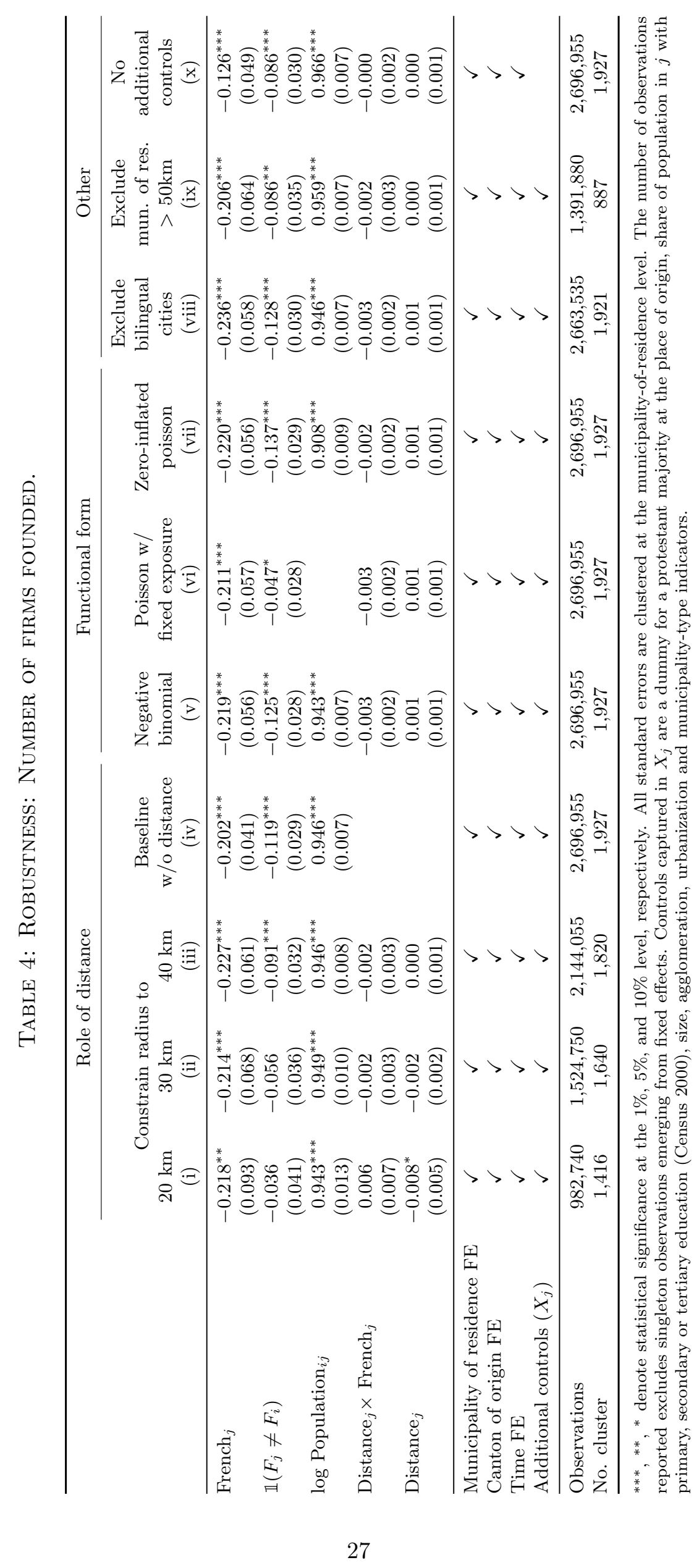


We present further robustness exercises in Table 11 in the Appendix. Those results additionally show that the results are insensitive to using municipalityof-residence $\times$ year fixed effects, to excluding the control for $\mathbb{1}\left(F_{j} \neq F_{i}\right)$, to controlling for individuals who never left their place of origin, to considering only the 10 biggest cities in Switzerland as places of residence, to considering all but the 10 biggest cities in Switzerland, to altering the definition of the language border and define the border $D_{j}=0$ at the French municipalities that are closest to the language border ${ }^{23}$, and finally, to considering a second-order polynomial of distance.

\section{Cultural Differences in Firm Characteristics}

Having established strong cultural differences in new firm foundations in the previous section the natural follow-up question arising is how these newly founded firms differ by cultural origin of the firm founder. To do so, we will compare the newly founded firms along four dimensions: Industry composition, legal form, failure rates, and firm size.

\subsection{Industry Composition}

Using data provided by Bisnode Business Information Group we can match 6digit industry classifications (NOGA 2008) to $99 \%$ of the firms in our sample. We plot the distribution of the major industries for both types of cultural origin in Figure 5. These industries account for more than $85 \%$ of newly founded firms in Switzerland.

A first glance at the distribution reveals remarkable similarities. The sheer comparison of frequencies does, however, not allow for any causal conclusions since we do not control for any covariates such as demand conditions at the level of the municipality of the firm. To achieve the latter, we rerun our baseline

\footnotetext{
${ }^{23}$ Compare Eugster and Parchet (2018).
} 
Figure 5: INDUSTRY SHARES OF NEWLY FOUNDED FIRMS BY CULTURAL BACKGROUND OF FOUNDER.

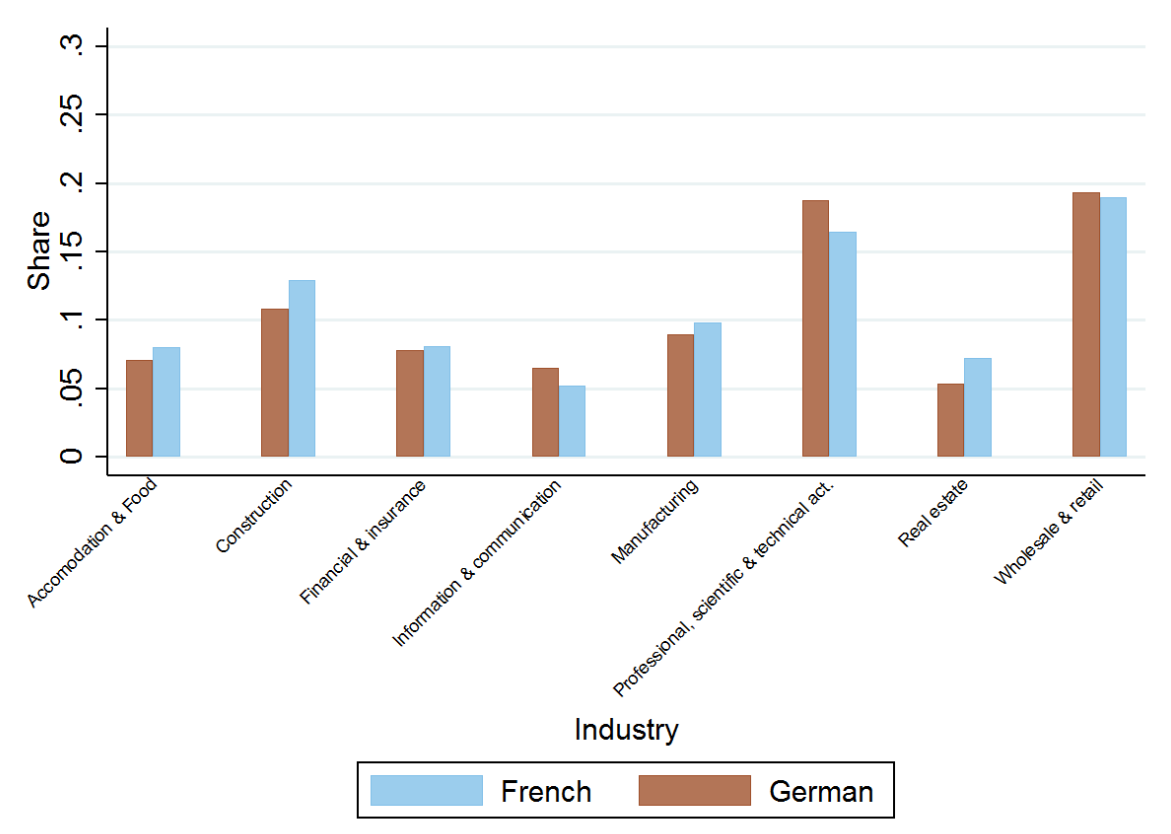

specification (6) separately for the eight major industries in Switzerland. Hence, $N_{i j c t}$ corresponds to the number of firms founded in a specific industry with each industry corresponding to a column in Table 5. The estimated coefficient on the role of cultural origin is overall very close to the main effect in Table 3 even though it is generally estimated less precisely due to the increase in observations with zeros and the accompanied loss in observations through their absorption in fixed effects.

\subsection{Legal Form}

The second heterogeneity we consider is the legal form of the firm. The three most common legal forms, Corporation, Individual Enterprise, and Limited Liability Company make up $97 \%$ of all firms founded in Switzerland. One could consider the legal form as a proxy for the size of the firm and for the willingness of the firm founder to take financial risks in case of bankruptcy: While Corporations and Limited Liability Companies cover debt only with firm assets, firm 


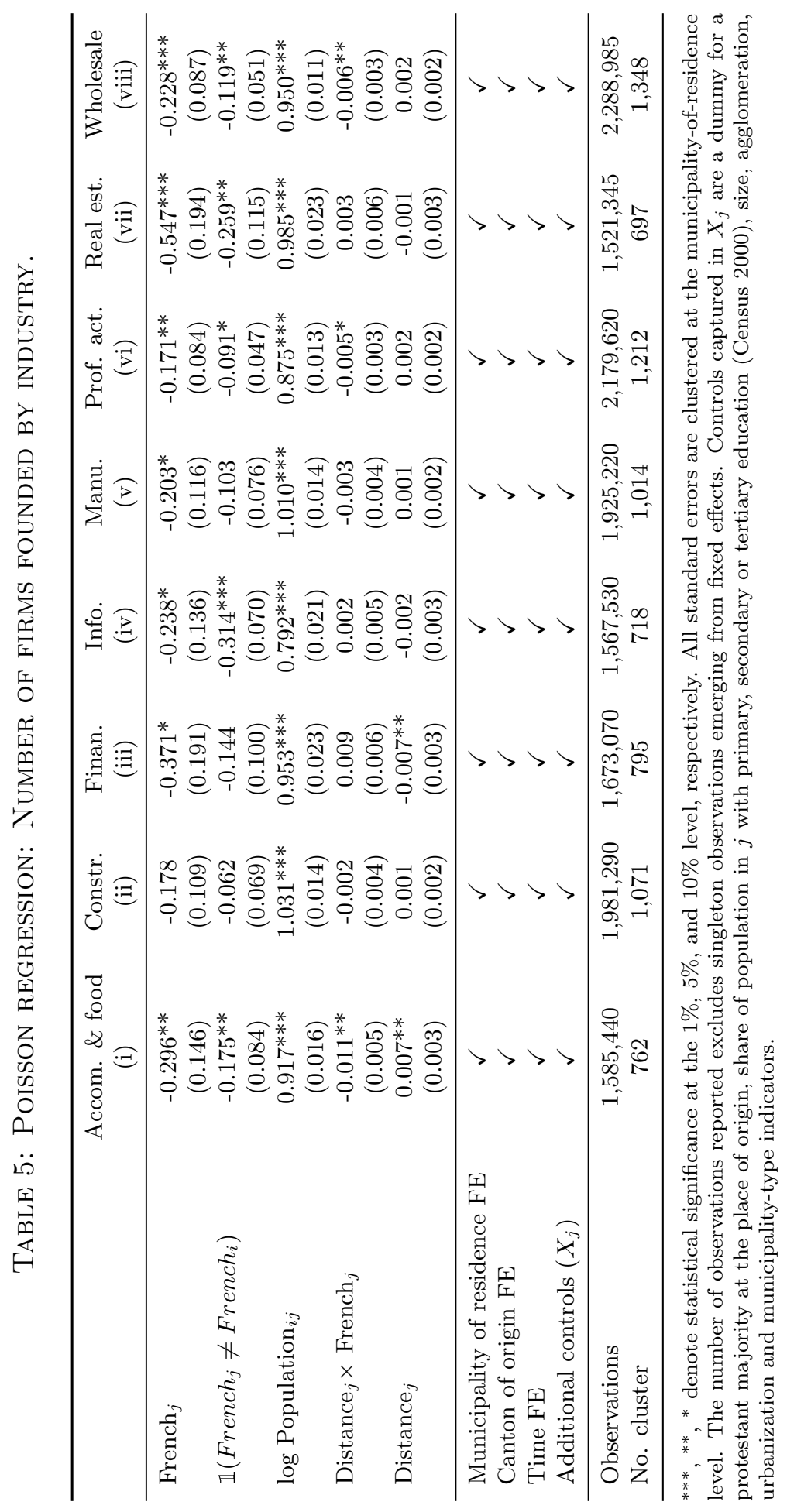


TAble 6: Poisson Regression: Number of Firms Founded BY LEGAL FORM.

\begin{tabular}{lccc}
\hline & $\begin{array}{c}\text { Corporation } \\
(\mathrm{i})\end{array}$ & $\begin{array}{c}\text { Indiv. enterprise } \\
\text { (ii) }\end{array}$ & $\begin{array}{c}\text { LLC } \\
\text { (iii) }\end{array}$ \\
\hline French $_{j}$ & $-0.256^{*}$ & $-0.194^{* * *}$ & $-0.234^{* * *}$ \\
& $(0.132)$ & $(0.058)$ & $(0.069)$ \\
$\mathbb{1}\left(\right.$ French $_{j} \neq$ French $\left._{i}\right)$ & -0.034 & $-0.194^{* * *}$ & $-0.102^{* * *}$ \\
& $(0.075)$ & $(0.035)$ & $(0.036)$ \\
$\log$ Population $_{i j}$ & $0.988^{* * *}$ & $0.912^{* * *}$ & $0.947^{* * *}$ \\
& $(0.016)$ & $(0.008)$ & $(0.009)$ \\
Distance $_{j} \times$ French $_{j}$ & 0.006 & $-0.005^{* * *}$ & $-0.007^{* * *}$ \\
& $(0.004)$ & $(0.002)$ & $(0.002)$ \\
Distance $_{j}$ & $-0.004^{*}$ & $0.002^{*}$ & $0.003^{* *}$ \\
& $(0.002)$ & $(0.001)$ & $(0.001)$ \\
\hline Municipality of residence FE & $\checkmark$ & $\checkmark$ & $\checkmark$ \\
Canton of origin FE $_{\text {Time FE }}$ & $\checkmark$ & $\checkmark$ & $\checkmark$ \\
Additional controls $\left(X_{j}\right)$ & $\checkmark$ & $\checkmark$ & $\checkmark$ \\
\hline Observations & $\checkmark$ & $\checkmark$ & $\checkmark$ \\
No. cluster & $2,303,175$ & $2,507,820$ & $2,468,595$ \\
\hline
\end{tabular}

$* * *,{ }^{* *},{ }^{*}$ denote statistical significance at the $1 \%, 5 \%$, and $10 \%$ level, respectively. All standard errors are clustered at the municipality-of-residence level. The number of observations reported excludes singleton observations emerging from fixed effects. Controls captured in $X_{j}$ are a dummy for a protestant majority at the place of origin, share of population in $j$ with primary, secondary or tertiary education (Census 2000), size, agglomeration, urbanization and municipality-type indicators.

owners account for firm debt with their private assets in case of bankruptcy of an Individual Enterprise. At the same time, Corporations and Limited Liability Companies require more assets and are more expensive to found and run.

We follow the same strategy as before and rerun Equation 6 with different dependent variables according to their legal form. Table 6 shows the results. The estimated coefficient on French-speaking place of origin is virtually identical in all three columns and coincides with the counterpart in the baseline regression in column (i) of Table 3.

\subsection{Probability of Failure}

The third firm characteristic we consider is the probability of firm failure. The probability of firm failure can be seen as a valid first proxy for the quality of a firm. In contrast to the previous analyses, we will run a slightly different 
estimation that relies, however, on the same identification assumptions that were introduced in Section 4.1. The new unit of observation is the firm itself rather than the number of firms founded in a certain population. This allows for a richer set of controls such as the legal form or the industry of the firm. Also, this setting allows for absorbing fixed effects at the level of the municipality the firm is located in. To assess the probability of failure of a firm $f$ we estimate variants of the following linear probability model for firms founded by individuals with origin in municipality $j$ and canton $c$ founded in municipality $i$ at time $t$,

$$
Y_{i j c t f}=\alpha_{i t}+\kappa_{c}+\delta F_{j}+\zeta D_{j}+\eta F_{j} \times D_{j}+\beta X_{j}+\lambda Z_{f}+\epsilon_{i j c t},
$$

where $Y_{i j c t f}$ is an indicator for firm failure, $F_{j}$ is an indicator for place of origin in the French-speaking region, $D_{j}$ is the shortest road distance from the place of origin to the language border, and $X_{j}$ captures place of origin controls. We subsume firm characteristics, such as their legal form or sector dummies, in the vector $Z_{f}$. Further, all regressions absorb fixed effects for the municipality where a firm is based times the founding year $\left(\alpha_{i t}\right)$ and canton fixed effects for places of origin $\left(\kappa_{c}\right)$. Standard errors are heteroskedasticity-robust and clustered at municipality where the firm is based.

We consider three different outcomes to access failure of newly founded firms, based on the classification in the commercial registry. The broadest measure covers any deregistration from the commercial registry. As this may not capture failure accurately the second measure covers only liquidation, closure, and bankruptcies, while the last measure focuses solely on bankruptcies.

We report two specifications for each of the three outcomes, once with and once without additional place of origin and firm-level controls and report them in Table 7. In all six columns we estimate a precise zero effect at the language border. I.e. there is no difference in probability of firm failure between firms founded by individuals with place of origin on the German-speaking side compared to 


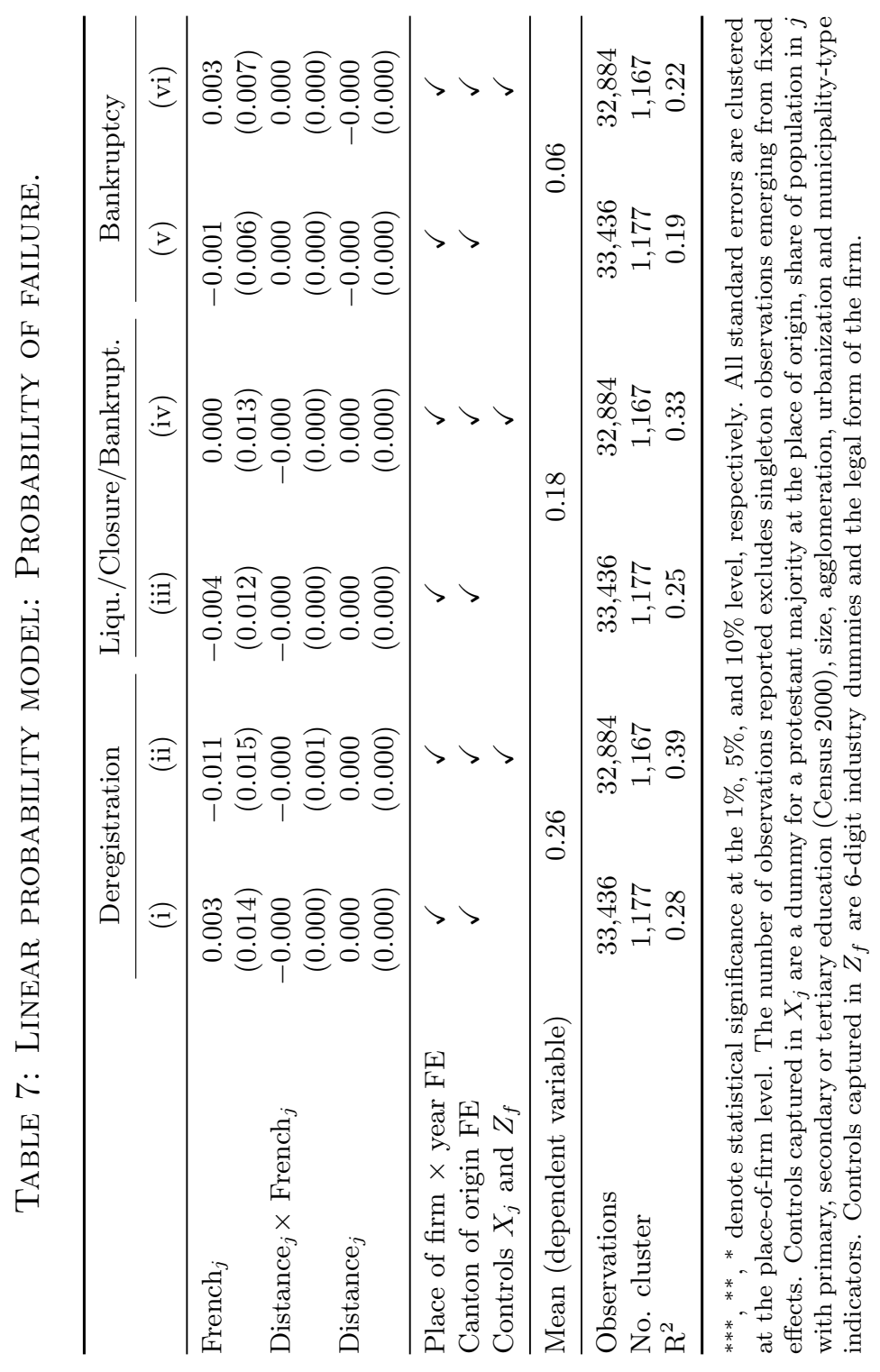


Table 8: Summary Statistics of the ORBIS Panel.

\begin{tabular}{lccccc}
\hline \multicolumn{1}{c}{ Variable } & Mean & SD & Min. & Max. & N \\
\hline Year & & & 2007 & 2015 & 123,864 \\
$\log ($ No of employees $)$ & 0.921 & 1.054 & 0 & 9.054 & 123,864 \\
$\mathbb{1}($ Employees $>1)$ & 0.514 & 0.5 & 0 & 1 & 123,864 \\
$\log$ (Revenue) & 7.522 & 1.187 & 2.639 & 16.423 & 76,540 \\
French-speaking origin, $F_{j}$ & 0.348 & 0.476 & 0 & 1 & 123,864 \\
Distance to language border, $D_{j}$ & 10.26 & 27.233 & -49.094 & 49.466 & 123,864 \\
Firm age & 5.179 & 3.375 & 0 & 13 & 123,760 \\
\hline
\end{tabular}

individuals with place of origin on the French-speaking side of the language border. All results are robust to replacing municipality-of-registration $\times$ foundingyear fixed effects by municipality-of-registration fixed effects and to omitting industry controls or varying their digit-level. Moreover, the significance levels are not affected by cluster choice.

\subsection{Firm Size}

Using the unique commercial register identifier we can merge data on employment and revenue as provided by the ORBIS database (Van Dijk, 2018) to the firms founded. The ORBIS data covers the years 2007-2015 but the coverage varies across years. While only a subset of firms is covered for the years before 2012, almost the universe of firms is covered for the years from 2012-2015. Generally, coverage is better for employment than for revenue. Of the 40,193 firms that are in our baseline sample, we can match ORBIS data with at least one non-missing employment observation to 31,729 firms. Summary statistics are provided in Table 8 .

We run separate regressions for age groups in order to approximate the role of cultural origin over the life cycle of the firm. The firm-level analysis is analogous to the analysis of firm failure in Equation (7):

$$
Y_{i j c t f}=\alpha_{i t}+\kappa_{c}+\delta F_{j}+\zeta D_{j}+\eta F_{j} \times D_{j}+\beta X_{j}+\lambda Z_{f}+\epsilon_{i j c t f}
$$


where $Y_{i j c t f}$ is an indicator of firm size (log number of employees, a dummy for employer-firms, and $\log$ revenue), $F_{j}$ is an indicator for place of origin in the French-speaking region, $D_{j}$ is the shortest road distance from the place of origin to the language border, and $X_{j}$ captures place of origin controls. We subsume firm characteristics, such as their legal form or sector dummies, in the vector $Z_{f}$. Further, all regressions absorb fixed effects for the municipality where a firm is based times the founding year $\left(\alpha_{i t}\right)$ and canton fixed effects for places of origin $\left(\kappa_{c}\right)$. Standard errors are heteroskedasticity-robust and clustered at municipality where the firm is based.

We report estimated coefficients on French-speaking place-of-origin by age of the firm in Figure 6. Panel (a) shows the analysis for the log number of employees as dependent variable, Panel (b) uses an indicator for firms with more than one employee (i.e. employer-firms), and Panel (c) shows the estimated coefficients for the regression on log revenue. The figures indicate that, if anything, firms founded by entrepreneurs with French-speaking origin are somewhat smaller in the first years after firm foundation. At the latest after three years, firms of founders with French- and German-speaking origin employ the same number of employees and are equally likely to be employer-firms, while there is little difference in revenues across cultural origin. The estimated coefficients are nearly identical when conditioning on the set of surviving firms.

Taken together, the four analyses in this chapter reveal that firms that are founded by entrepreneurs with French- and German-speaking cultural origin are remarkably similar. This finding combined with the strong effect of cultural origin on firm foundation can help us to shed light on the specific nature of the cultural determinants driving the results. We will do so by considering a theoretical model of entrepreneurial choice in the next section. 
Figure 6: DiFFERENCES IN FIRM SIZE BY ORIGIN OF FIRM-FOUNDERS AND AGE OF FIRMS.

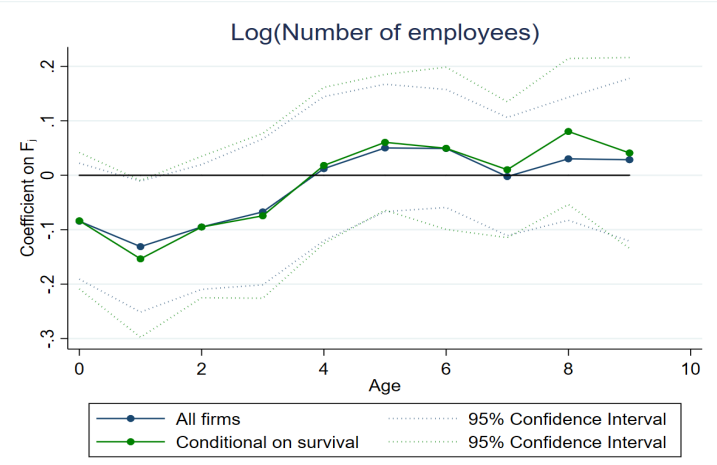

(A) LOG(NuMBER OF EMPLOYEES)

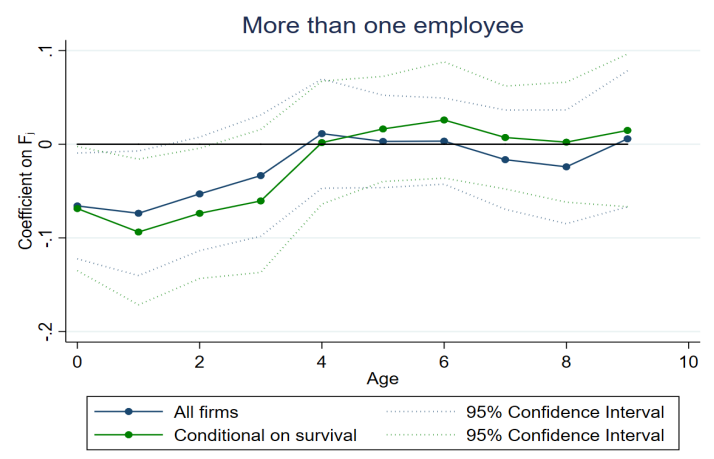

(B) INDICATOR FOR MORE THAN ONE

EMPLOYEE

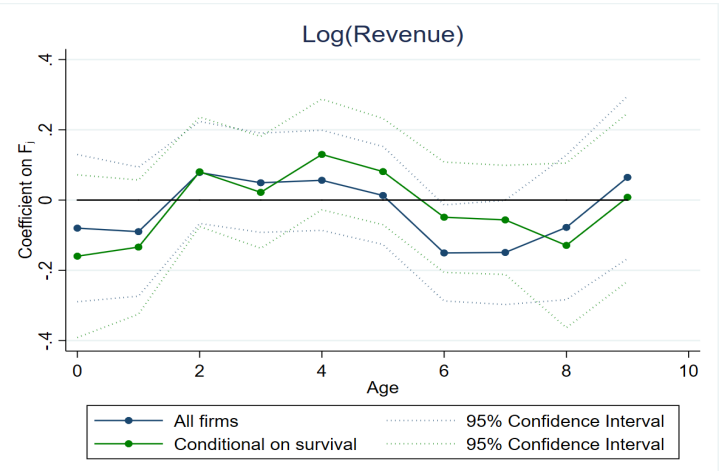

(C) LOG(REVENUE)

Coefficients are obtained estimating Equation (8) by age group. Standard errors are clustered at the place-of-firm level. The regressions include fixed effects on the municipality-of-registration $\times$ year-ofregistration level and the canton-of-origin level. Controls captured in $X_{j}$ are a dummy for a protestant majority at the place of origin, share of population in $j$ with primary, secondary or tertiary education (Census 2000), size, agglomeration, urbanization and municipality-type indicators. Controls captured in $Z_{f}$ are 6-digit industry dummies and the legal form of the firm. 


\section{A Stylized Model of Entrepreneurial Choice}

The question on the nature of entrepreneurs and its cultural distribution is at the heart of a historical debate among economists - most prominently by Knight (1921) and Schumpeter (1934). Knight (1921) underlines the role of risk bearing as one of the fundamental characteristics of an entrepreneur while Schumpeter (1934) emphasizes the innovative capacity and quality of the entrepreneur. Translated into economic models, Lucas Jr (1978) considers a model where the more able agents become entrepreneurs while Kihlstrom and Laffont (1979) provide us with a model of risk averse agents with the least risk averse becoming the entrepreneurs. More recently, Hurst and Pugsley (2015) consider the sheer preference for entrepreneurship to be driving particularly small business formation.

Apart from these three personality traits, an extensive literature in economics and management has identified a host of other drivers of entrepreneurial choice (see, e.g. Jovanovic, 1982; Evans and Jovanovic, 1989; Clementi and Hopenhayn, 2006). However, for our purpose, we can focus on these three parameters guided by the identification strategy of the empirical setting for two reasons. First, since all effects are identified within the very same environment (within a municipality) we will not focus on parameters that can be taken as constant in this environment such as wage rates, taxes, costs of entering a business, or bankruptcy laws. Second, the spatial identification design at the language border (but within cantons) allows us to hold constant factors such as the social and professional background of both the potential entrepreneurs and their ancestors.

We propose the following stylized model, abstracting from any general equilibrium considerations. Consider a set of agents on the interval $[0,1]$ with each agent being denoted by $\alpha$. Each agent's utility is described by the function $U=u(I, \alpha)+\gamma(\alpha) \times \mathbb{I}($ entrepreneur $)$, where $I \geq 0$ denotes income and $\gamma(\alpha)$ is a constant that additively increases utility if an agent chooses to become 
an entrepreneur (to allow for non-pecuniary benefits of entrepreneurship as in Hurst and Pugsley, 2015). Further assume that $u^{\prime}(\cdot)>0$ and $u^{\prime \prime}(\cdot) \leq 0$ exist and are continuous. Analogously to Kihlstrom and Laffont (1979), we assume that the Arrow-Pratt coefficient of relative risk aversion $\eta(I, \alpha)=-\frac{u^{\prime \prime}(I, \alpha)}{u^{\prime}(I, \alpha)}$ is nondecreasing in $\alpha$.

Agents can choose to be regular workers obtaining a risk-free income $w$ or to become entrepreneurs, obtaining a risky income $y=a(\alpha) x$, where $a(\alpha) \geq 0$ denotes entrepreneurial ability, and $x$ is the realization of a random variable with density function $f(x)$ with support $[0, \bar{x}]$. Hence, the expected profits from entrepreneurship for agent $\alpha$ are

$$
\mathbb{E}(\pi(\alpha))=a(\alpha) \int_{0}^{\bar{x}} x f(x) d x
$$

and increasing in entrepreneurial ability. Agents choose to become entrepreneurs if the expected utility from doing so, $\mathbb{E}\left(u^{e}(\alpha)\right)$ is at least as high as the expected utility from being a worker, $\mathbb{E}\left(u^{w}(\alpha)\right)$ :

$$
\mathbb{E}\left(u^{e}(\alpha)\right)=\int_{0}^{\bar{x}} u(a(\alpha) x, \alpha) f(x) d x+\gamma(\alpha) \geq u(w, \alpha)=\mathbb{E}\left(u^{w}(\alpha)\right)
$$

The upper graph in Figure 7 (a) illustrates the trade-off faced by agents with a given level of entrepreneurial ability across different levels of relative risk aversion by plotting their expected utility as a worker and as an entrepreneur in $\eta$-space. The expected profits of an entrepreneur's firm are constant across $\eta$. The marginal entrepreneur is exactly indifferent between setting up a business and working for a risk-free wage. The lower graph in Figure 7 (a) links the marginal entrepreneur to its relative position in the distribution of relative risk aversion in the population. The share of the population becoming entrepreneurs is defined by the mass to the left of the marginal entrepreneur. 
Figure 7: EQUILIBRIUM SHARE OF ENTREPRENEURS UNDER DIFFERENT PARAMETER DISTRIBUTIONS ACROSS POPULATIONS.

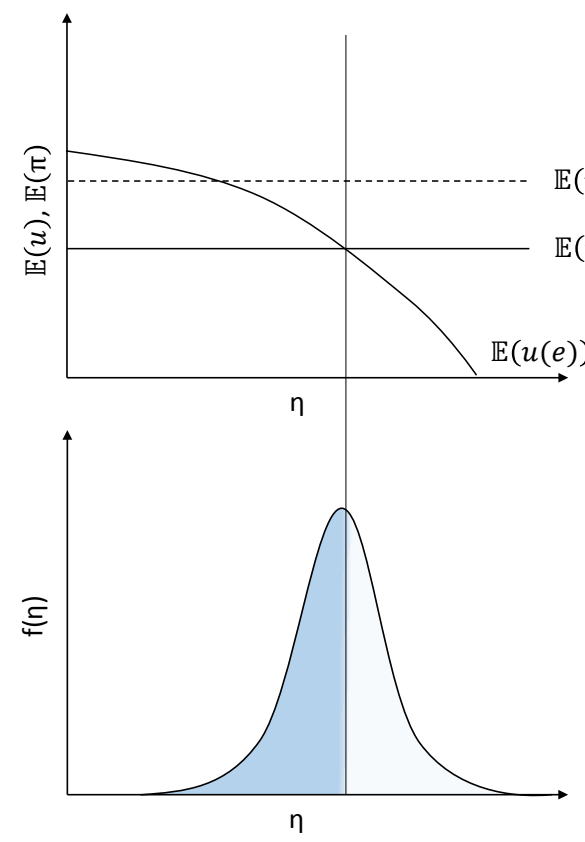

(a) Identical parameters

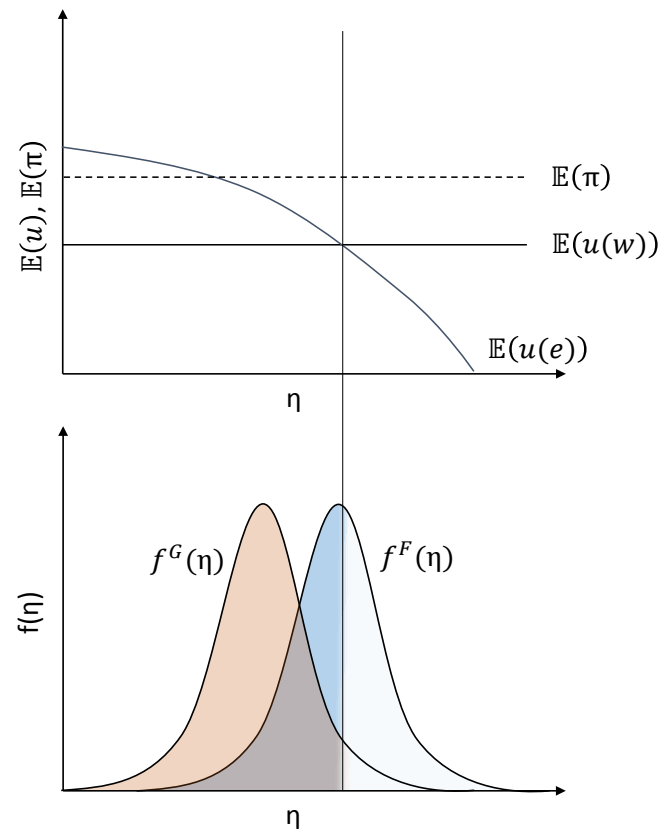

(C) Differences in Risk AVERSion

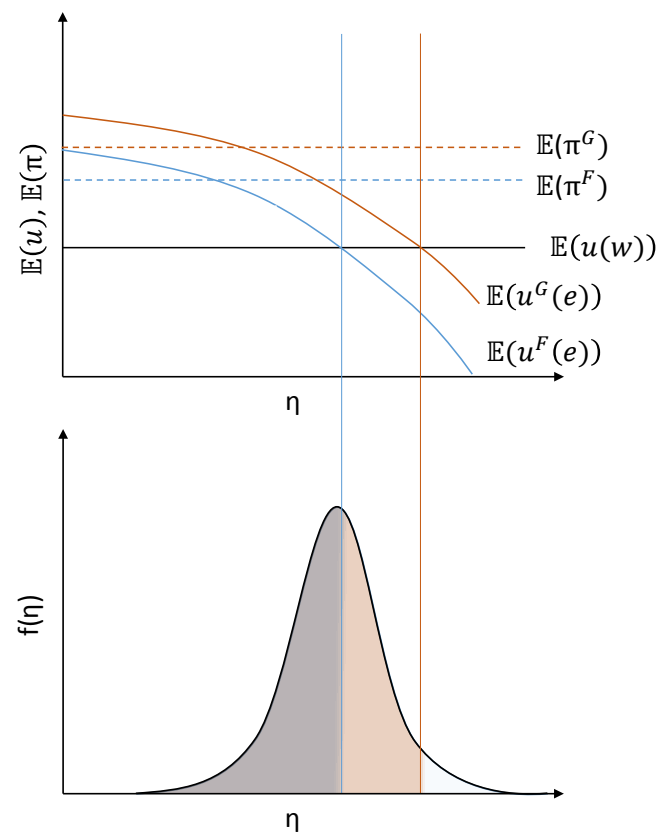

(B) DifFERENCES IN ENTREPRENEURIAL ABILITY

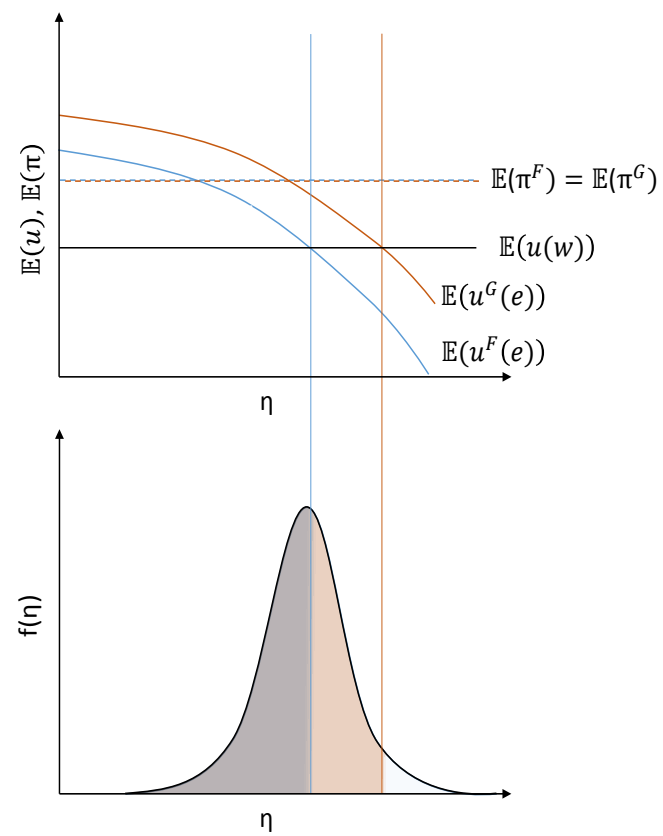

(D) Differences in PREFERENCES FOR ENTREPRENEURSHIP 
In order to reconcile the patterns highlighted in the empirical section we want to discuss different distributional assumptions of the parameters across populations with French- and German-speaking cultural origin such that we observe i) a higher rate of entrepreneurship among those with German-speaking origin but ii) identical success rates (average profits) in the set of founded firms. Let us denote any population-specific characteristics by $G$ and $F$ for Germanand French-speaking cultural origin, respectively.

We examine 3 cases. First, consider a different distribution of entrepreneurial abilities in the two populations such that $a^{G}>a^{F}$ as is depicted in Figure 7 (b). This implies an upward shift of the expected utility of an entrepreneur with German-speaking roots as well as an upward shift of the expected profits generated by these firms. Assuming the distribution of relative risk aversion and entrepreneurial preferences to be the same in both populations, there should be a higher share of entrepreneurs in the population with German-speaking cultural origin as it is observed in the data. But in contrast to the empirical evidence, the average firm founded by citizens with German-speaking cultural origin should also perform better than the average firm founded by those with French-speaking cultural origin.

Second, consider the distribution of abilities and entrepreneurial preferences to be identical but the distribution of relative risk aversion of the population with German-speaking origin to be first-order stochastically dominated by the distribution of the population with French-speaking origin, as in Figure 7 (c). Hence, the average risk aversion of citizens with German-speaking origin is lower, compared to citizens with French-speaking origin. The marginal entrepreneur has the same risk aversion in both populations but the cut-off corresponds to a higher share of entrepreneurs among citizens with German-speaking roots. The expected performance of firms founded by both populations would, however, be identical in this case, as average abilities of firm founders are the same. 
Finally, Figure 7 (d) depicts the case where entrepreneurship leads to higher non-pecuniary benefits among citizens with German-speaking roots. As in case (b) the utility schedule shifts up and the marginal entrepreneur among the population with German-speaking roots is more risk averse than the marginal entrepreneur with French-speaking roots. This corresponds to a higher share of the population that becomes an entrepreneur. In contrast to case (b), expected profits of founded firms are not affected.

To sum up, the main empirical results can be reconciled in a stylized model where Swiss with French-speaking origin have on average a higher risk aversion (case (c)) or obtain lower non-pecuniary benefits from entrepreneurship (case (d)). There is, however, one important difference: Case (c) implies that the average entrepreneur with French-speaking origin is more risk-averse than the average entrepreneur with German-speaking cultural heritage, while case (d) implies the opposite. This distinction can help us to further narrow down the main channel through which cultural origin affects entrepreneurship.

To do so, we consider three independent data sets that survey the above mentioned personal characteristics for the Swiss population and the subset of Swiss entrepreneurs. All data sets report the language in which the interview was conducted which we use as a proxy for French-speaking and German-speaking cultural origin, respectively. The respective data sets are (i) a data set compiled by Falk et al. (2017) in order to collect data on the global distribution of preference parameters, (ii) the Global Entrepreneurship Monitor (GEM), and (iii) the European Value Survey (EVS). We control for date fixed effects where this information is available and focus on the subset of men when they can be separately identified. ${ }^{24}$ Importantly, GEM data allows us to identify entrepreneurs which helps us to assess differences in characteristics across the population of

\footnotetext{
${ }^{24}$ Potential control variables provided vary across data. We present the baseline results without controls to ensure comparability of the three separate datasets since no control variables are available for the dataset by Falk et al. (2017). Additional controls such as income, age, and education are available for both GEM and EVS data, their inclusion in the analysis does not change any of the qualitative results.
} 
entrepreneurs with a French-speaking origin and a German-speaking origin, respectively.

Table 9 presents the results. Both, Falk et al. (2017) and GEM survey risk attitudes. While Falk et al. (2017) reports risk aversion parameters, GEM asks the respondents if fear of failure would prevent respondents from starting a business. Both measures indicate that the French-speaking Swiss population is more risk averse than the German-speaking population. The same holds for the subset of entrepreneurs, which speaks in favor of the risk channel in the model above (case (c)).

Columns (iv) and (v) report the self-assessed entrepreneurial skills of the respondents. Specifically, the GEM survey asks if the respondent has the required skills to start a business. As conjectured based on the theoretical model, the skill level does not vary significantly between French- and German-speaking Swiss, neither for the subset of entrepreneurs nor the overall population.

Finally, the EVS survey allows us to assess preferences towards two job characteristics that are typically considered to be relevant for entrepreneurs: 'a responsible job' and 'opportunity to use initiative'. We find that both characteristics are significantly more important to German-speaking Swiss which can be interpreted as a preference for entrepreneurial-like activities. The latter speaks in favor of case (d) in the theoretical model.

In line with the theoretical predictions, correlational evidence confirms that both risk aversion and preferences for entrepreneurial activity might play a role in explaining the differences in entrepreneurial activity across cultural background while skill differences seem to be less relevant. Importantly, the fact that even within the subset of entrepreneurs, French-speaking entrepreneurs seem to exhibit stronger risk aversion than German-speaking entrepreneurs, speaks strongly in favor of risk aversion playing the dominant role in explaining the empirical regularities in the setting exploited in this paper. 


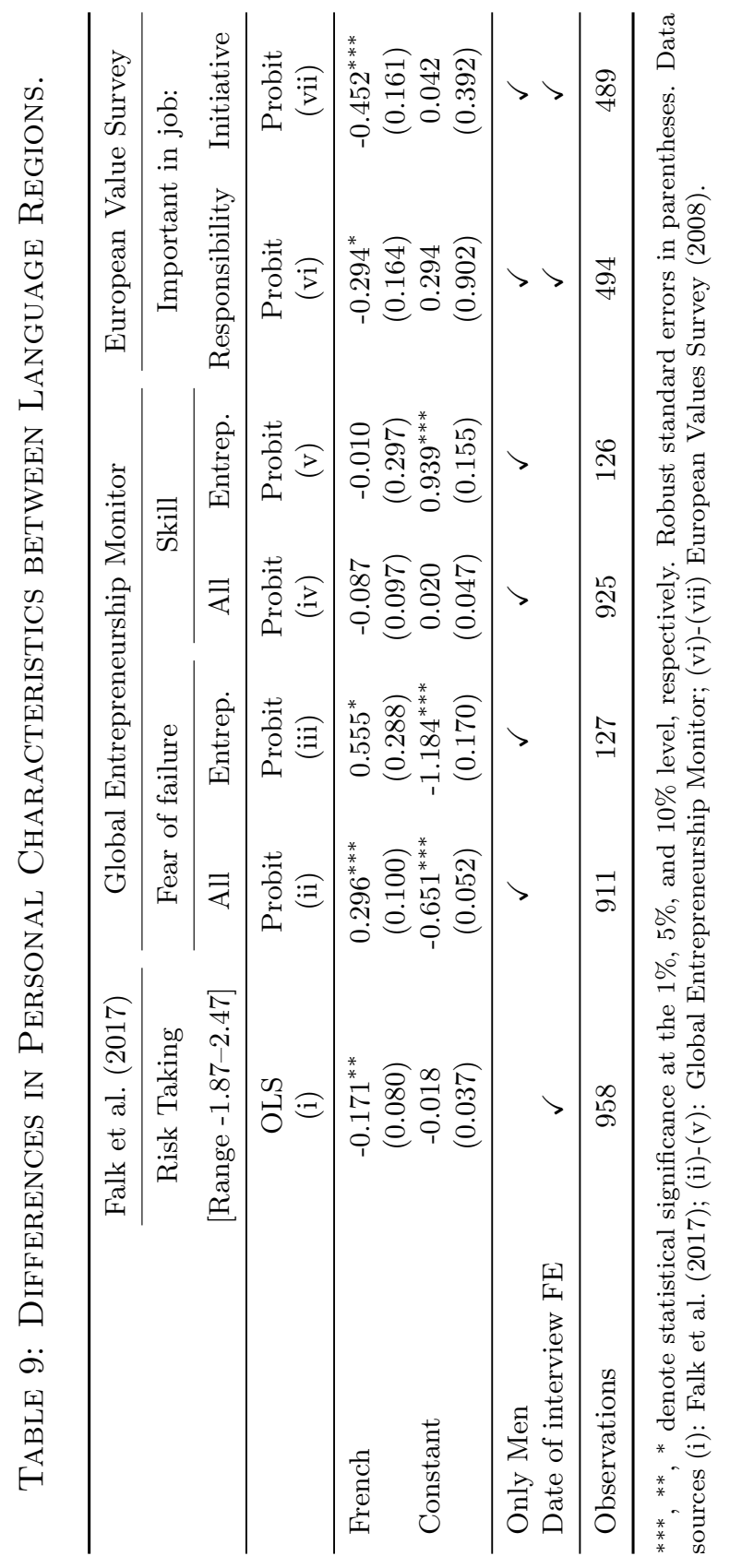




\section{Aggregate Implications}

Up to know, we have shown that cultural origin plays an important role in entrepreneurship. Specifically, we have estimated that people with Germanspeaking origins found $20 \%$ more firms compared to people with French-speaking origin. In this section, we will try to put these numbers into a broader context and assess their economic importance.

Since newly founded firms have been shown to be very similar across founders, the differential impact of cultural origin on aggregate outcomes can be approximated by imposing a differential entry rate of $20 \%$ in models of economic growth while abstracting from productivity differences across founded firms. In particular, entry affects aggregate productivity growth through its effect on the pace of reallocation of resources across establishments. Since entrants are typically subject to a higher level of productivity than exiting firm and exhibit different productivity dynamics compared to incumbent firms, aggregate productivity is strongly influenced by the number of entering firms. Using US data, Foster et al. (2001) find that net entry of plants account for $25 \%$ of U.S. manufacturing productivity growth. Based on data from Chile and South Korea, Asturias et al. (2017) show that net entry is even more important in times of fast growth with its contribution to aggregate productivity growth rising to $37-58 \%$.

Since data on firm-level productivities for the Swiss economy is not available, we will assess the importance of net entry for the Swiss economy by focusing on employment instead. Data on the universe of Swiss establishments from 20112015 reveals that entry indeed plays an important role in the dynamics of the Swiss economy. From 2011 to 2015, around 150,000 new full-time equivalent jobs were created all over Switzerland. Decomposing these numbers, reveals that around 100,000 of these jobs were created by firms that existed throughout the 
period, 463,000 by new entrants, whereas 413,000 jobs were lost due to exiting firms. ${ }^{25}$

A simple back-of-the-envelope calculation allows us to approximate the aggregate implications of the differences in entry rates across cultural groups for the Swiss economy. ${ }^{26}$ Over the period of investigation (2002-2016) 171,271 firms were founded by men with German-speaking origin and 42,257 by men with Frenchspeaking origin. Of these firms, 127,667 and 30,728 still existed at the end of our sample period, respectively. Based on our estimates, $0.20 \times 127,667 \approx 25,533$ less firms would exist today if the entry rate of Swiss men with German-speaking origin and French-speaking origin was the same. According to Bureau van Dijk's ORBIS data, the average firm existing in Switzerland at the beginning of 2016 that was born in the period 2002-2015, has 5 employees (including the owner). For a subset of the STATENT data that can be merged to data on firm entry in Switzerland for the period 2001-2013, the average employment for a firm aged 12 or less years is 4.5 employees in 2013 which accounts for 3.6 full time equivalents. ${ }^{27}$ This implies that the sheer difference in entry rates amounts to 115,000 128,000 jobs that have been created over the sample period and still existed at the end of 2016. These numbers amount to $2.5 \%$ of all jobs in Switzerland. ${ }^{28}$

\footnotetext{
${ }^{25}$ These numbers are based on the STATENT (Statistik der Unternehmensdemographie) data provided by the Swiss Federal Statistical Office.

${ }^{26}$ Note that summary statistics presented in Tables 12 and 13 in the Appendix suggest that the firms of the regression sample are largely representative for the universe of firms founded by Swiss men in the period of investigation.

${ }^{27}$ Note that from 2012 onwards, ORBIS covers the universe of Swiss firms in terms of founding date and employment. To see this, consider the number of firms covered in STATENT (Statistik der Unternehmensdemographie) which amounts to 597,216 compared to 601,745 firms in ORBIS. Differences in these numbers typically arise from different accounting of establishments.

${ }^{28}$ Clearly, this approach abstracts from any general equilibrium considerations. In particular, it does not take into account feedback effects stemming from scarce resources such as labor. We believe that this resource constraint is of a smaller concern as Switzerland is very well integrated with the labor market of the European Union.
} 


\section{Conclusion}

This paper studies how culture affects entrepreneurship. We use a quasi experimental setting in Switzerland that allows for a comparison of the entrepreneurial activities of Swiss citizens with different cultural background but who live in the same municipality and are hence, exposed to the same economic and institutional conditions. Applying a spatial regression discontinuity design, we find that individuals with cultural origin just on the German-speaking side of the language border found $20 \%$ more firms than their counterparts with cultural origin just on French-speaking side. At the same time, the types of these newly founded firms are identical in terms of industry composition, legal form, survival rate, and size.

Rationalizing these findings in a theoretical model of entrepreneurial choice suggests that the differences in entrepreneurship in this setting are more likely to be driven by differences in risk aversion and preferences for entrepreneurial activity rather than differences in skill. This conjecture is supported by survey evidence on the distribution of personal characteristics across Swiss cultural groups and the subset of Swiss entrepreneurs. Taken together, evidence points to risk aversion playing a dominant role in explaining the differences in entrepreneurial choice in the Swiss setting.

Back-of-the-envelop calculations point to sizable aggregate implications of the cultural differences in entrepreneurial choice. In Switzerland, the differences account for around 120,000 additional jobs that have been created by Germanspeaking Swiss citizens over the period of investigation, amounting to $2.5 \%$ of today's jobs. 


\section{References}

Alesina, A. and P. Giuliano (2010). The power of the family. Journal of Economic Growth 15(2), 93-125.

Alesina, A. and P. Giuliano (2015). Culture and institutions. Journal of Economic Literature 53(4), 898-944.

Alesina, A., P. Giuliano, and N. Nunn (2013). On the origins of gender roles: Women and the plough. The Quarterly Journal of Economics 128(2), 469530.

Asturias, J., S. Hur, T. J. Kehoe, and K. J. Ruhl (2017). Firm entry and exit and aggregate growth. Working Paper 23202, National Bureau of Economic Research.

Audretsch, D. B., I. Grilo, and A. R. Thurik (2007). Explaining Entrepreneurship and the Role of Policy: A Framework. In Handbook of Research on Entrepreneurship Policy. Edward Elgar Publishing.

Audretsch, D. B., M. C. Keilbach, and E. E. Lehmann (2006). Entrepreneurship and economic growth.

Becker, S. O. and L. Woessmann (2009). Was Weber wrong? A human capital theory of protestant economic history. The Quarterly Journal of Economics 124(2), 531-596.

Benabou, R. and J. Tirole (2006). Belief in a just world and redistributive politics. The Quarterly Journal of Economics 121(2), 699-746.

Britt, C. (2013). Swiss roots. [Online; accessed 4-January-2018].

Brown, M., C. Henchoz, and T. Spycher (2018). Culture and financial literacy: Evidence from a within-country language border. Journal of Economic Behavior \& Organization 150, 62-85. 
Büchi, C. (2003). Röstigraben. Das Verhältnis ziwschen deutscher und französischer Schweiz. Geschichte und Perspektiven, Verlag Neue Zürcher Zeitung.

Caicedo, F. V. (2018). The mission: Human capital transmission, economic persistence, and culture in south america. The Quarterly Journal of Economics.

Cameron, A. C. and P. K. Trivedi (2013). Regression Analysis of Count Data (2 ed.). Econometric Society Monographs. Cambridge University Press.

Chen, M. K. (2013). The effect of language on economic behavior: Evidence from savings rates, health behaviors, and retirement assets. The American Economic Review 103(2), 690-731.

Christ, T. (2006). Historical dictionary of switzerland. [Online; accessed 4January-2018].

Clementi, G. L. and H. A. Hopenhayn (2006). A theory of financing constraints and firm dynamics. The Quarterly Journal of Economics 121(1), 229-265.

Davidsson, P. (1995). Culture, structure and regional levels of entrepreneurship. Entrepreneurship 83 Regional Development 7(1), 41-62.

Davidsson, P. and J. Wiklund (1997). Values, beliefs and regional variations in new firm formation rates. Journal of Economic psychology 18(2), 179-199.

Eugster, B., R. Lalive, A. Steinhauer, and J. Zweimüller (2011). The demand for social insurance: Does culture matter? The Economic Journal 121(556), $413-448$.

Eugster, B., R. Lalive, A. Steinhauer, and J. Zweimüller (2017). Culture, work attitudes and job search: Evidence from the swiss language border. Journal of the European Economic Association. 
Eugster, B. and R. Parchet (2018). Culture and taxes. Journal of Political Economy, forthcoming.

Evans, D. S. and B. Jovanovic (1989). An estimated model of entrepreneurial choice under liquidity constraints. Journal of political economy 97(4), 808827.

Falk, A., A. Becker, T. Dohmen, B. Enke, D. Huffman, and U. Sunde (2017). Global evidence on economic preferences. The Quarterly Journal of Economics.

Federal Statistical Office (2000). Eidg. Volkszählung, harmonisierte Personendaten 1970-2000. Technical report, Neuchâtel.

Fernandez, R. and A. Fogli (2009). Culture: An empirical investigation of beliefs, work, and fertility. American Economic Journal: Macroeconomics 1(1), 146177.

Foster, L., J. Haltiwanger, and C. Krizan (2001). Aggregate productivity growth: Lessons from microeconomic evidence. In New Developments in Productivity Analysis, pp. 303-372. National Bureau of Economic Research, Inc.

Giuliano, P. (2007). Living arrangements in Western Europe: Does cultural origin matter? Journal of the European Economic Association 5(5), 927-952.

Glaeser, E. L., S. P. Kerr, and W. R. Kerr (2015). Entrepreneurship and urban growth: An empirical assessment with historical mines. Review of Economics and Statistics 97(2), 498-520.

Guiso, L., P. Sapienza, and L. Zingales (2006). Does culture affect economic outcomes? Journal of Economic Perspectives 20(2), 23-48.

Hayton, J. C., G. George, and S. A. Zahra (2002). National culture and entrepreneurship: A review of behavioral research. Entrepreneurship theory and practice $26(4), 33$. 
Hoselitz, B. F. (1957). Noneconomic factors in economic development. The American Economic Review 47(2), 28-41.

Hurst, E. G. and B. W. Pugsley (2015). Wealth, tastes, and entrepreneurial choice. Technical report, National Bureau of Economic Research.

Jovanovic, B. (1982). Selection and the evolution of industry. Econometrica: Journal of the Econometric Society, 649-670.

Kihlstrom, R. E. and J.-J. Laffont (1979). A general equilibrium entrepreneurial theory of firm formation based on risk aversion. Journal of Political Economy $87(4), 719-748$.

Knight, F. H. (1921). Risk, uncertainty and profit. New York: Hart, Schaffner and Marx.

Lassmann, A. and C. Busch (2015). Revisiting native and immigrant entrepreneurial activity. Small Business Economics 45(4), 841-873.

Leff, N. H. (1979). Entrepreneurship and economic development: The problem revisited. Journal of economic literature 17(1), 46-64.

Lucas Jr, R. E. (1978). On the size distribution of business firms. The Bell Journal of Economics, 508-523.

Lüdi, G. (2013). Historical dictionary of Switzerland. [Online; accessed 4January-2018].

Luttmer, E. F. and M. Singhal (2011). Culture, context, and the taste for redistribution. American Economic Journal: Economic Policy 3(1), 157-79.

Nunn, N. (2009). The importance of history for economic development. Annual Review of Economics 1(1), 65-92. 
Obschonka, M., M. Stuetzer, S. D. Gosling, P. J. Rentfrow, M. E. Lamb, J. Potter, and D. B. Audretsch (2015). Entrepreneurial regions: Do macropsychological cultural characteristics of regions help solve the "knowledge paradox" of economics? PloS one 10(6), e0129332.

Parker, S. C. (2004). The economics of self-employment and entrepreneurship. Cambridge University Press.

Schumpeter, J. A. (1934). The theory of economic development (translation of second german edition by redvers opie). Cambridge, MA, Harvard University.

Schweizer, R. J. (2011). Historical dictionary of Switzerland. [Online; accessed 4-January-2018].

Steinhauer, A. (2013). Identity, working moms, and childlessness: Evidence from Switzerland. mimeo.

Stuetzer, M., M. Obschonka, D. B. Audretsch, M. Wyrwich, P. J. Rentfrow, M. Coombes, L. Shaw-Taylor, and M. Satchell (2016). Industry structure, entrepreneurship, and culture: An empirical analysis using historical coalfields. European Economic Review 86, 52-72.

Swiss Confederation (2013). Federal act on the acquisition and loss of swiss citizenship. [Online; accessed 4-January-2018].

Swiss Confederation (2018). Liste der Heimatorte oder Bezeichnungen der Heimatorte der Schweiz, welche keine politischen Gemeinden mehr sind. [Online; accessed 4-January-2018].

Van Dijk, B. (2018). Orbis database. Bureau Van Dijk Electronic Publishing.

Weber, M. (1905). The protestant ethic and the" spirit" of capitalism. In Archiv für Sozialwissenschaften und Sozialpolitik. 


\section{A Appendix}

[For online publication]

\section{A.1 Historical Migration Patterns}

TABle 10: Linear REgression: DOMESTIC MIGRATION PATTERNS.

\begin{tabular}{lc}
\hline & $\log \left(P_{i j}\right)$ \\
\hline $\log \left(\right.$ Distance $\left._{i j}\right)$ & $-0.567^{* * *}$ \\
& 0.010 \\
$\mathbb{1}\left(F_{j} \neq F_{i}\right)$ & $-0.262^{* * *}$ \\
& 0.021 \\
$\mathbb{1}\left(F_{j} \neq F_{i}\right) \times F_{j}$ & -0.030 \\
& 0.031 \\
$\log \left(\right.$ Size $\left._{j}\right)$ & $0.358^{* * *}$ \\
& 0.009 \\
\hline
\end{tabular}

Municipality of residence $\mathrm{FE}$

Canton of origin FE

Additional controls $\left(X_{j}\right)$ $\checkmark$

\begin{tabular}{lc}
\hline $\mathrm{R}^{2}$ & 0.40 \\
Observations & 185,506 \\
\hline
\end{tabular}

$* * *, * *, *$ denote statistical significance at the $1 \%, 5 \%$, and $10 \%$ level, respectively. All standard errors are clustered at the municipalityof-residence level. Controls captured in $X_{j}$ are a dummy for a protestant majority at the place of origin, share of population in $j$ with primary, secondary or tertiary education (Census 2000), agglomeration, urbanization and municipality-type indicators. 


\section{A.2 Balance of Place of Origin Variables at Language Border}

We provide evidence that typical (and potentially non-cultural) determinants of entrepreneurship are balanced at the language border in Figures 8 and 9. Figure 8 shows that the status index - a measure by the Swiss statistical office encompassing income, education, and job prestige - as well as the average income does not change discontinuously at the language border. While historical information on these variables is not available at the municipality level, the history of population growth of the municipalities at the language border can tell us more about parallel economic developments at the language border. First, since population growth is strongly affected by economic conditions the continuity of the variable at the language border over time strongly indicates that people with cultural origin from directly to the right or to the left of the language border have their origins not from strikingly different economic environments, especially, considering that domestic migration at this language border was always unrestricted. Second, there is no indication that migration away from the respective places of origin has taken place at different points in time for individuals with French- or German-speaking origin, respectively. 
Figure 8: Balance of Place of origin CHARACTERistics at THE LANGUAGE BORDER.

(A) Status index

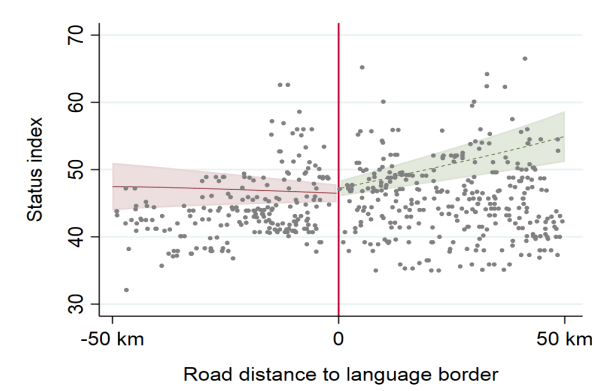

(B) Gross incomce per capita

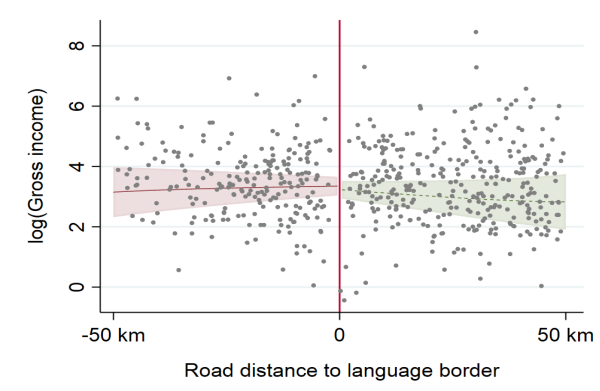

(C) Gross incomce per taxpayer

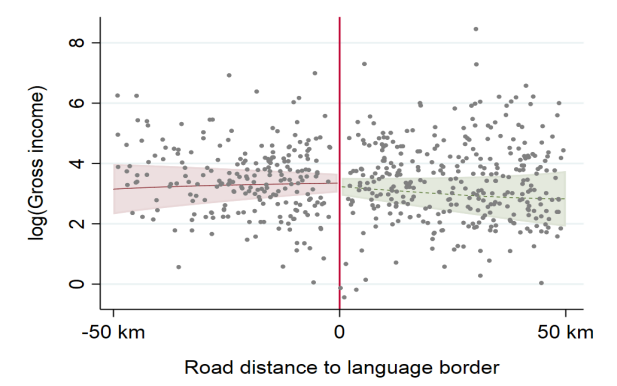

Note: Information provided by the Swiss Statistical Office based on the Census 2000. 
Figure 9: Balance of Population Growth RAtes at the LANGUAGe BORDER OVER TIME.

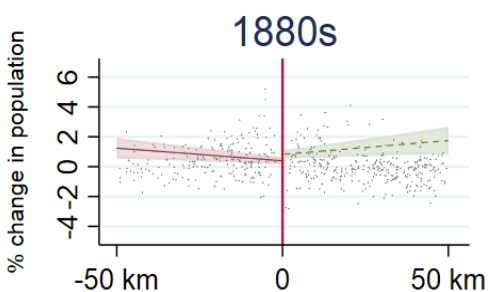

Road distance to language border

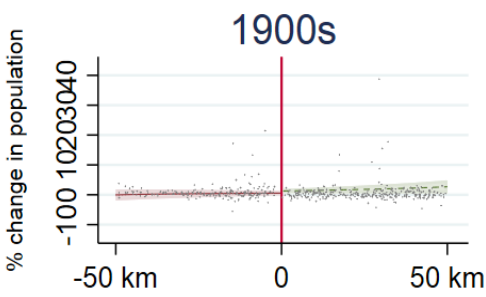

Road distance to language border

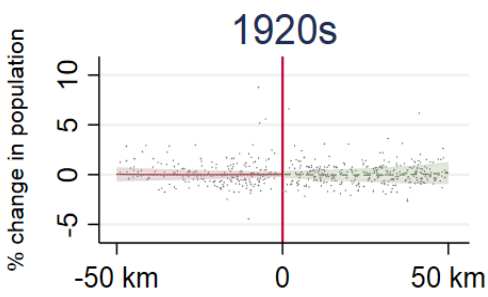

Road distance to language border

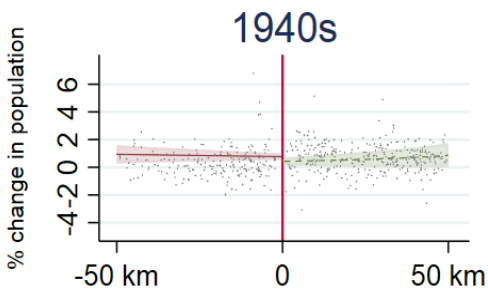

Road distance to language border

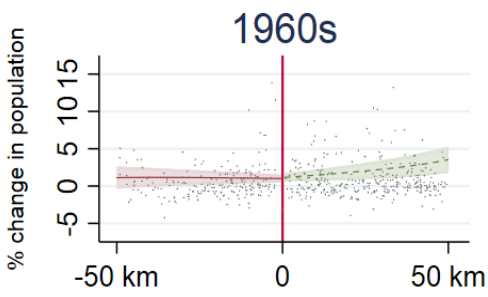

Road distance to language border

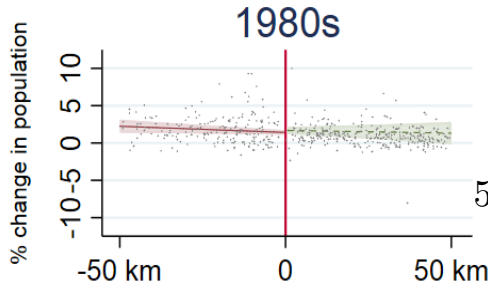

Road distance to language border

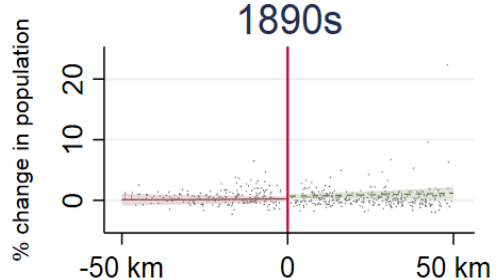

Road distance to language border

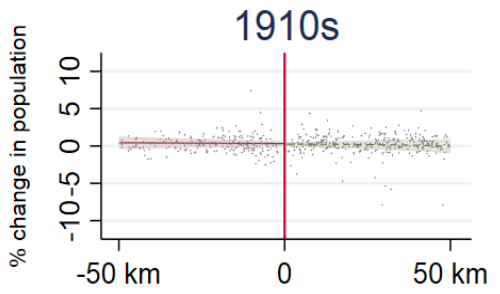

Road distance to language border

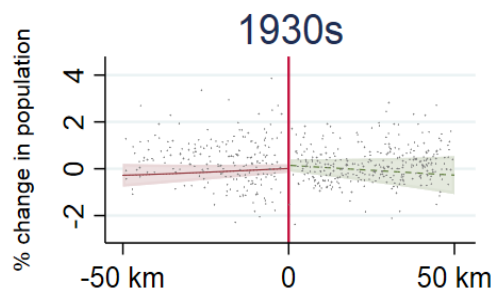

Road distance to language border

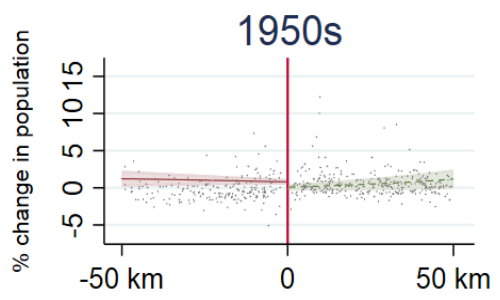

Road distance to language border

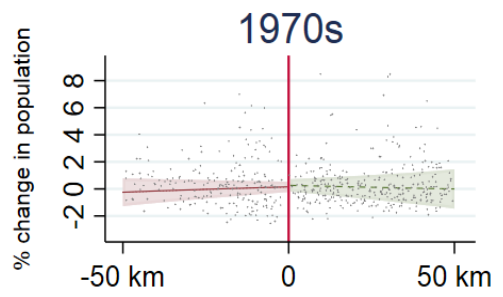

Road distance to language border

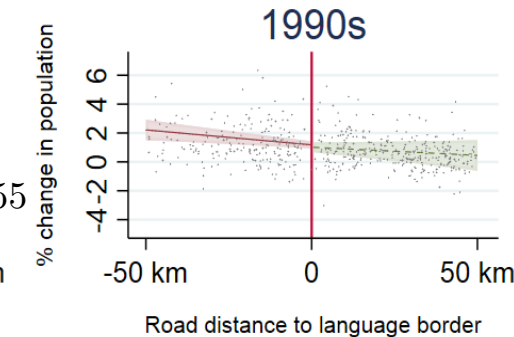




\section{A.3 Additional Robustness}

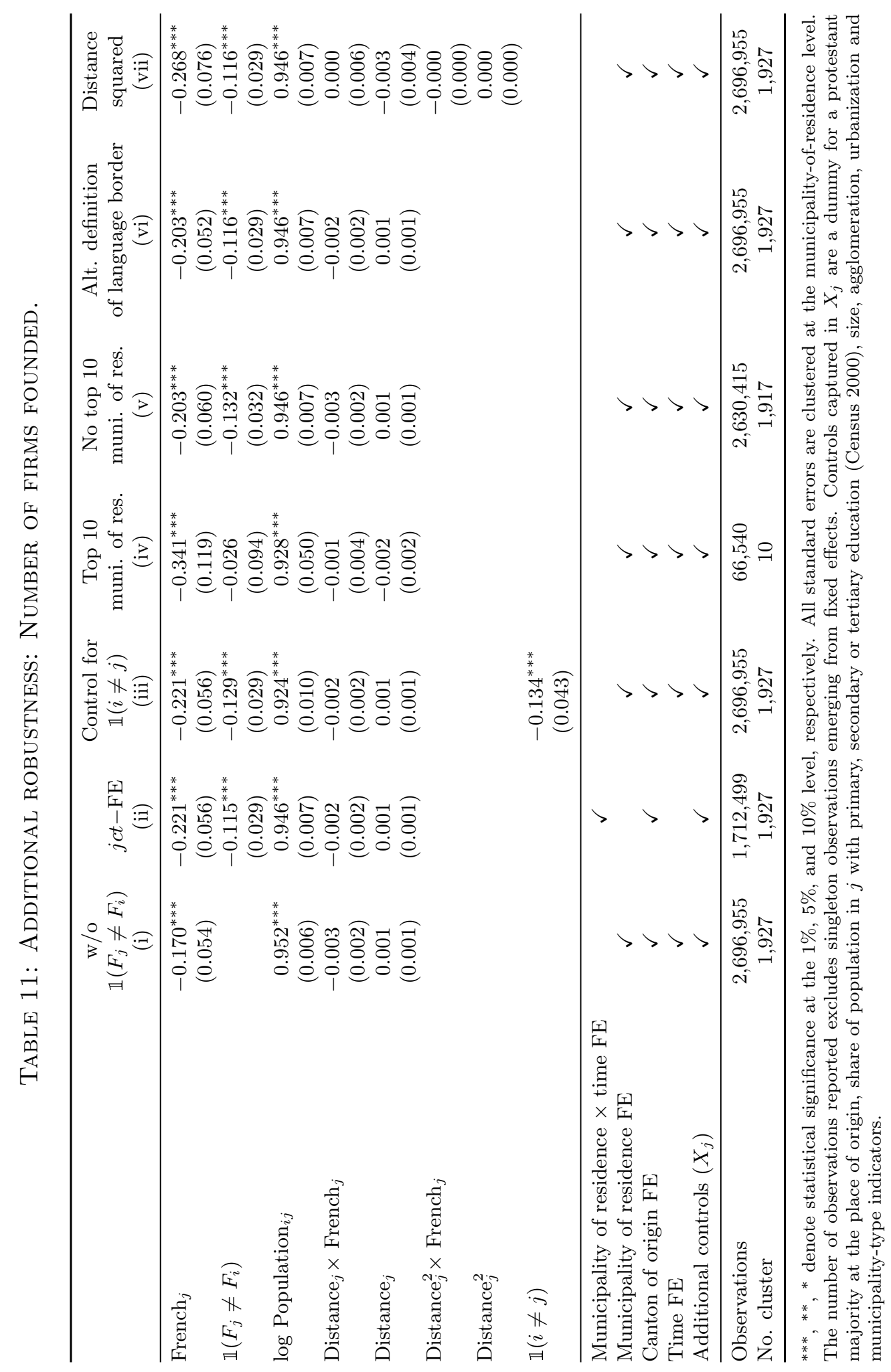




\section{A.4 Representativeness of Sample for Switzerland}

Table 12: Summary Statistics of Firm Registry Data for Founders with Origins around the Language Border and the Full Dataset.

\begin{tabular}{|c|c|c|c|c|}
\hline & \multicolumn{2}{|c|}{ Sample } & \multicolumn{2}{|c|}{ Universe } \\
\hline & Mean & $\mathrm{SD}$ & Mean & SD \\
\hline \multicolumn{5}{|l|}{ Business Success } \\
\hline Deregistration & 0.261 & 0.439 & 0.256 & 0.436 \\
\hline Liquid./Closure/Bankruptcy & 0.185 & 0.388 & 0.174 & 0.379 \\
\hline Bankruptcy & 0.057 & 0.231 & 0.056 & 0.23 \\
\hline \multicolumn{5}{|l|}{ Sector Composition } \\
\hline Accomodation \& food service & 0.073 & 0.260 & 0.061 & 0.239 \\
\hline Administrative \& support service & 0.048 & 0.215 & 0.050 & 0.219 \\
\hline Agriculture & 0.000 & 0.000 & 0.000 & 0.003 \\
\hline Arts, entertainment \& recreation & 0.015 & 0.123 & 0.016 & 0.124 \\
\hline Construction & 0.114 & 0.318 & 0.102 & 0.303 \\
\hline Education & 0.013 & 0.112 & 0.014 & 0.116 \\
\hline Electricity, gas, steam supply & 0.003 & 0.056 & 0.003 & 0.051 \\
\hline Financial \& insurance & 0.078 & 0.268 & 0.085 & 0.279 \\
\hline Human health \& social work & 0.019 & 0.136 & 0.019 & 0.136 \\
\hline Information \& communication & 0.059 & 0.237 & 0.066 & 0.249 \\
\hline Manufacturing & 0.091 & 0.288 & 0.080 & 0.271 \\
\hline Other services & 0.018 & 0.133 & 0.017 & 0.128 \\
\hline Professional, scientific \& technical act. & 0.177 & 0.382 & 0.199 & 0.399 \\
\hline Public administration \& defence & 0.001 & 0.027 & 0.001 & 0.027 \\
\hline Real estate & 0.059 & 0.236 & 0.056 & 0.230 \\
\hline Transportation \& storage & 0.026 & 0.160 & 0.027 & 0.162 \\
\hline Water supply, sewerage, waste management & 0.003 & 0.056 & 0.002 & 0.049 \\
\hline Wholesale \& retail trade & 0.190 & 0.392 & 0.192 & 0.394 \\
\hline Industry unknown & 0.011 & 0.105 & 0.010 & 0.101 \\
\hline \multicolumn{5}{|l|}{ Legal Form } \\
\hline Corporation & 0.283 & 0.450 & 0.313 & 0.464 \\
\hline Individual enterprise & 0.350 & 0.477 & 0.325 & 0.468 \\
\hline Cooperative & 0.004 & 0.066 & 0.005 & 0.070 \\
\hline LLC & 0.332 & 0.471 & 0.330 & 0.470 \\
\hline Limited partnership & 0.028 & 0.165 & 0.025 & 0.157 \\
\hline Other & 0.002 & 0.049 & 0.003 & 0.053 \\
\hline Observations & \multicolumn{2}{|c|}{40,193} & \multicolumn{2}{|c|}{188,234} \\
\hline
\end{tabular}


Table 13: Summary Statistics of the Merged ORBIS Data for the SAmple of Founders with Origins around the Language Border AND the Full Dataset.

\begin{tabular}{lccccccc}
\hline & \multicolumn{3}{c}{ Sample } & & \multicolumn{3}{c}{ Universe } \\
\cline { 2 - 4 } \cline { 7 - 8 } \multicolumn{1}{c}{ Variable } & Mean & SD & Obs. & & Mean & SD & Obs. \\
\hline $\log$ (No of employees) & 0.921 & 1.054 & 123,864 & & 0.927 & 1.048 & 584,177 \\
$\log$ (Revenue) & 7.436 & 1.242 & 92,680 & & 7.468 & 1.229 & 425,951 \\
\hline
\end{tabular}

